\title{
Reliability Effects of Maintenance on TNEP Considering Preventive and Corrective Repairs
}

\author{
Meisam Mahdavi, Hassan Monsef, Member, IEEE, and Rubén Romero, Senior Member, IEEE
}

\begin{abstract}
The aim of this paper is to investigate maintenance effects on system reliability and transmission network expansion planning considering line loading and repairs. For this purpose, the maintenance cost is formulated taking into account transient and permanent forced outage rates, as well as durations of planned and forced outage. Also, transmission reliability is modeled considering load shedding (LS) and energy not supplied (ENS) criteria. LS index is calculated for transient forced outages and ENS criterion is computed for permanent forced outages, and planned outage rates and durations. Furthermore, the effects of line loadings on transmission system reliability are formulated through the transient and permanent forced outage rates. The proposed model was tested on the IEEE 24-bus and 30-bus test systems, and the results are discussed.
\end{abstract}

Index Terms-Corrective and preventive repairs, forced and planned outages, line loading, line maintenance, TNEP.

\section{NOMENCLATURE}

\section{A. Sets:}

$\Omega^{b}, \Omega^{c} \quad$ Set of all buses and all corridors;

$\Omega^{e c} \quad$ Set of existing corridors including lines;

$\Omega^{s} \quad$ Set of existing corridors including substations;

$\Omega^{l b}, \Omega^{g b} \quad$ Set of load buses and generation buses.

B. Constants:

$\hat{a}_{f, n m}^{i j}, \hat{b}_{q, n m}^{i j}$

The ratio of the change in power flow on the line connected between buses $n$ and $m$ to the change in generation on bus $f$ and to the change in demand on bus $q$ when line $j$ in corridor $i$ fails;

\begin{tabular}{l}
$C^{L}$ \\
$C_{i}^{C}, C_{i}{ }^{S}$ \\
$C_{i j}^{R}$ \\
$C_{i j}^{M}$ \\
\hline
\end{tabular}

Per unit cost of power losses (\$/MWh);

Construction cost of a line circuit and a substation $138 / 230 \mathrm{kV}$ in corridor $i(\$)$;

Replacement cost of line $j$ in corridor $i(\$)$;

Fixed maintenance cost per kilometer of line $j$ in corridor $i(\$ / \mathrm{km})$;

Manuscript received May 2, 2016; revised September 24, 2016; accepted November 12, 2016. Date of publication December 15, 2016; date of current version August 17, 2017. Paper no. TPWRS-00680-2016.

M. Mahdavi and H. Monsef are with the Research Center of Power System Operation and Planning Studies, School of Electrical and Computer Engineering, College of Engineering, University of Tehran, Tehran 14395-515, Iran (e-mail: me.mahdavi@alumni.ut.ac.ir; hmonsef@ut.ac.ir).

R. Romero is with the Department of Electrical Engineering, Faculty of Engineering of Ilha Solteira, Paulista State University, Ilha Solteira CP 31, Brazil (e-mail: ruben@dee.feis.unesp.br).

Color versions of one or more of the figures in this paper are available online at http://ieeexplore.iee.org.

Digital Object Identifier 10.1109/TPWRS.2016.2640178

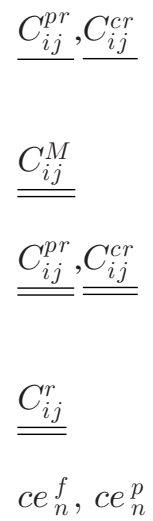

$D_{n}, G_{n}$

$D_{n}^{0}$

$G_{n}^{\min }$

$G_{n}^{\max }$

$k_{i j}^{\mathrm{Max}}$

$\ell_{i}, V_{i}$

$m_{i j}, M_{i j}$

$n_{i j}^{l 0}, n_{i j}^{r l}$

$\overline{n_{i}}, \underline{n_{i}}$

$\overline{P_{i}}, \overline{P_{n m}}$

$\overline{P_{i j}}$

$r_{i}, \gamma_{i}$

$T, k^{L}$

$v_{i j}$

VOLL $L_{n}$ $\underline{\lambda_{i j}}, r_{i j}^{c r}$

$\underline{\lambda_{i j}^{f}, \lambda_{i j}^{t}}$
Fixed preventive and corrective repair cost per kilometer of line $j$ in corridor $i$ $(\$ / \mathrm{km})$;

Hourly fixed maintenance cost per kilometer of line $j$ in corridor $i(\$ / \mathrm{km}-\mathrm{h})$;

Hourly fixed preventive and corrective repair cost per kilometer of line $j$ in corridor $i(\$ / \mathrm{km}$ h);

Hourly fixed repair cost per kilometer of line $j$ in corridor $i(\$ / \mathrm{km}-\mathrm{h})$;

Cost of one MWh energy not supplied on bus $n$ for permanent forced and planned outages (\$/MWh);

Total demand and generation on bus $n$ at the end of the planning horizon (MW);

Total demand on bus $n$ at the beginning of the planning horizon (MW);

Minimum generation on bus $n$ (MW);

Maximum generation on bus $n$ (MW);

Maximum maintenance cost coefficient for line $j$ in corridor $i$;

Length $(\mathrm{km})$ and voltage level $(\mathrm{kV})$ of corridor $i$

Feature constant of line $j$ in corridor $i$ and its maximum value;

Initial operation period and regular life for line $j$ in corridor $i$ (year);

Maximum and initial number of circuits in corridor $i$;

Maximum permissible active power of corridor $i$ and maximum permissible active power transmitted from bus $n$ to $m$ (MW);

Maximum active power of line $j$ in corridor $i$ (MW);

Resistance $(\Omega / \mathrm{km})$ and susceptance $\left(\Omega^{-1} / \mathrm{km}\right)$ of each circuit per kilometer of corridor $i$;

Planning horizon (year) and losses coefficient; Decision variable that is 1 when replacement does not happen for line $j$ in corridor $i$;

Value of lost load (VOLL) for bus $n$ (\$/MW); Basic value of forced outage rate (1/year) and permanent forced outage duration (h) for line $j$ in corridor $i$;

Basic value of permanent and transient forced outage rate for line $j$ in corridor $i$ (1/year); 
$\underline{\mu_{i j}}, r_{i j}^{p r}$

Basic value of planned outage rate (1/year) and duration (h) for line $j$ in corridor $i$.

C. Variables:

$k_{i j} \quad$ Maintenance cost coefficient for line $j$ in corridor $i$;

$L S_{n}^{i j} \quad$ Load shedding of bus $n$ due to the outage of line $j$ in corridor $i(\mathrm{MW})$;

$n_{i}, n_{i}^{s} \quad$ Number of new circuits and substations in corridor $i$;

$\Delta \theta_{i} \quad$ Difference between the voltage phase angle of the start and end buses in corridor $i$ (radian).

D. Functions:

$C_{i j}^{M} \quad$ Total maintenance cost of line $j$ in corridor $i(\$)$;

$C_{i j}^{p r}, C_{i j}^{c r} \quad$ Total preventive and corrective repair cost of line

$j$ in corridor $i(\$)$;

$k_{i j}^{p r}, k_{i j}^{c r} \quad$ Preventive and corrective repair cost coefficients for line $j$ in corridor $i$;

$P_{i}, P_{n m} \quad$ Active power of corridor $i$ and active power transmitted from bus $n$ to $m$ (MW);

$P_{i j} \quad$ Active power of line $j$ in corridor $i$ (MW);

$P_{i}{ }^{L} \quad$ Active power losses in corridor $i$ (MW);

$P_{n m}^{i j} \quad$ Active power transmitted from bus $n$ to $m$ when line $j$ in corridor $i$ has failed (MW);

$\lambda_{i j}, r_{i j}^{c r} \quad$ Forced outage rate (1/year) and permanent forced outage duration (h) for line $j$ in corridor $i$;

$\lambda_{m i j} \quad$ Forced outage rate of line $j$ in corridor $i$ due to maintenance (1/year);

$\lambda_{i j}^{f}, \lambda_{i j}^{t}$

$\lambda_{m i j}^{f}, \lambda_{m i j}^{t}$

$\mu_{i j}, r_{i j}^{p r}$

$\zeta_{i j}, \chi_{i j}$

$\zeta_{i j}^{f}, \zeta_{i j}^{t}$

$\rho_{i j}$ Permanent and transient forced outage rate of line $j$ in corridor $i$ (1/year);

Permanent and transient forced outage rate of line $j$ in corridor $i$ due to maintenance (1/year); Planned outage rate (1/year) and duration (h) for line $j$ in corridor $i$;

Forced outage rate and mean time to repair (MTTR) coefficients of line $j$ in corridor $i$; Permanent and transient forced outage rate coefficients for line $j$ in corridor $i$; Line loading coefficient of line $j$ in corridor $i$.

\section{INTRODUCTION}

$\mathbf{T}$ HE construction of new transmission lines is necessary to help existing lines reliably meet customers' increasing demand for electric power. The main task of transmission network expansion planning (TNEP) is determining the optimal placement of new transmission lines in the network [1]. At the same time, some existing lines may be old [2] and can be replaced by new ones to increase transmission system reliability. However, the replacement of older transmission lines may be costly and uneconomical over the long term. This is a serious challenge for planners because whereas the replacement of transmission lines is costly, retaining the old lines in the network may degrade the system's reliability, and reliability is the essential factor in long-term planning. A way to tackle this difficulty is to enhance the network reliability by reducing of lost load via the construction of new transmission lines. Another way is to expand the transmission system in order to reduce lines' failure rate by decreasing the existing lines' loading. However, these methods may cause an unreasonable increase in the dimension and expansion cost of the network. Maintenance concepts can be employed to remove these drawbacks, because maintenance activities can help to improve system reliability [3] more efficiently. The maintenance can increase the reliability by decreasing both the failure rate and the MTTR of transmission lines, while two other methods can enhance the reliability by reducing only the failure rate of the lines. In addition, maintenance is less expensive than line construction. Nevertheless, in the paper, all three approaches are considered to solve the problem. After the publication of Garver's paper in 1970 [4], extensive research was conducted on transmission network expansion planning. Some of the studies that solved this problem by considering reliability criteria are reviewed here.

Kim et al. [5] considered fuel cost and loss of load (LOL) in transmission expansion planning using the maximum principle. The maximum principle is a mathematical method that can be used to solve linear optimization problems. Romero et al. [6] optimized the TNEP problem, considering the reliability criterion of LOL using simulated annealing (SA). However, the quality of solutions may be degraded with an increase in the network dimension. In order to overcome this drawback, Gallego et al. [7] proposed a parallel simulated annealing (PSA) approach to minimize the objective function of [6]. The simulation results showed that the proposed method gives better solutions than SA. Silva et al. [8] presented a new formulation for the expansion planning of a transmission network under uncertainty in load by inserting LOL in both the objective function and problem constraints. Binato et al. [9] optimized the transmission expansion and reliability costs with respect to VOLL of busses, using greedy randomize adaptive search procedure (GRASP). GRASP is an expert iterative sampling technique that is a useful heuristic method to solve nonlinear optimization problems. However, the local search procedure used in this approach leads to some difficulties in pruning, by comparison. Choi et al. [10] minimized the expansion cost of a transmission network by considering three reliability constraints. The first criterion stated that the total capacity of the branches involved in the minimum cut-set should be greater than the system peak load. The second and third criteria were the loss of load expectation (LOLE) and $\mathrm{N}-a(a \geq 1)$ contingency, respectively. Although the $\mathrm{N}-1$ index is a traditional reliability criterion in TNEP, it caused a large increase in expansion costs, because it provides $100 \%$ reliability for customers in a contingency state (single line outage). Later, they [11] employed two probabilistic reliability criteria of LOLE and expected energy not supplied (EENS) to minimize customer outage costs in transmission expansion planning. Silva et al. [12] formulated the TNEP by including loss of load cost (LOLC) in the objective function, using the ant colony optimization (ACO) technique. ACO is a helpful metaheuristic method to optimize the TNEP problem. Later, the authors [13] modeled the TNEP, considering network losses and the cost of load curtailment, based on the artificial immune system (AIS). They showed that this method is more efficient than ACO for transmission expansion planning. Leou [14] formulated the TNEP in a competitive electricity market 
by inserting the reliability cost (cost of load curtailment) and marginal price of generators in the cost function. Akbari Foroud et al. [15] modeled the TNEP problem as the minimization of three objective functions: investment cost of the lines, congestion cost, and cost of load curtailment due to line outages. Also, Yu et al. [16] considered the reliability indices of LOLC and the cost of load curtailment due to renewable resources in TNEP using Taguchi's orthogonal array testing (TOAT). TOAT finds the optimal plans by selecting the best scenarios on generation and demand uncertainties. In addition, Gupta et al. [17] added the reliability criteria of expected demand not served (EDNS) and expected generation not served (EGNS) to the objective function of the probabilistic TNEP problem. It was shown that when EDNS is minimized, the capacity of the existing lines should be upgraded, along with the addition of new transmission lines. Finally, Shortle et al. [18] optimized the transmission expansion planning problem in order to minimize the probability of cascading blackouts.

However, none of these studies have considered the effects of line maintenance on transmission system reliability; in other words, the TNEP problem has not been optimized simultaneously with maintenance. For this reason, more recently, the same authors considered in [19] maintenance effect on transmission expansion planning and solved the combined TNEP problem with maintenance. They showed that maintenance affects expansion costs by decreasing the replacement cost of old lines and increasing the value of the transmission system. They concluded that the line failure rates and number of repairs are reduced when maintenance actions increase. However, the proposed model could not efficiently describe the maintenance relationship to network reliability, because the maintenance effect on transmission reliability was formulated via lines' permanent forced and planned outage rates (lines' failure rate and MTTR), without considering their durations or transient outages. The permanent forced outage duration is the time interval required to repair and restore the failed transmission line. On the other hand, the planned outage duration is the time needed to remove line defects in regular intervals (MTTR). Outage durations cannot be ignored, because they have considerable values and an important role in determining network reliability. If outage durations are reduced, the interruption cost (cost of energy not supplied) decreases, and consequently, more reliable electric power is provided to customers. Also, transient outage rate of transmission lines play an important role in reliability calculations, because transient outages are more frequent than permanent outages. Consequently, in this paper, the lines' outage durations and transient forced outage rates are included in the problem formulation, and their relationships with the maintenance are modeled mathematically. Moreover, the authors in [19] have not considered the maintenance effects on the corrective repair of lines, even though corrective repair is more expensive than the maintenance and preventive repair. In addition, [19] has not investigated the effect of line loading on transient outages. Thus, in the present paper, a new framework is proposed for TNEP, which considers the line maintenance and loading effects on transient forced outage rates, as well as reliability effects of maintenance on forced and planned outage durations, and corrective repairs. The model is solved using the decimal codification genetic algorithm (DCGA) and the fmincon function, which is classical optimization technique in MATLAB. The main aims and contributions of the present study are:

1) To introduce the quantitative relationships among line maintenance, forced and planned outage durations, and transmission reliability.

2) To present mathematical formulations that investigate the reliability effects of line maintenance on corrective repair.

3) To formulate the maintenance effect on transient forced outages.

4) To describe the correlation of transient outages with transmission line loading.

\section{PROBLEM Formulation}

The TNEP problem is formulated by using the DC power flow model as a minimization of the objective function (1).

$$
\begin{aligned}
\min F= & \sum_{i \in \Omega^{c}} C_{i}^{C} n_{i}+\sum_{i \in \Omega^{s}} C_{i}^{S} n_{i}^{s}+\sum_{i \in \Omega^{c}} C_{i}^{L} \\
& +\sum_{i \in \Omega^{e c}} \sum_{j=1}^{n_{i}} v_{i j}\left[C_{i j}^{M}+C_{i j}^{p r}+C_{i j}^{c r}\right] \\
& +\sum_{n \in \Omega^{l b}} V O L L_{n} \sum_{i \in \Omega^{e c}} \sum_{j=1}^{n_{i}} L S_{n}^{i j} \lambda_{i j}^{t} \\
& +\sum_{n \in \Omega^{l b}} c e_{n}^{f} \sum_{i \in \Omega^{e c}} \sum_{j=1}^{n_{i}} L S_{n}^{i j} \lambda_{i j}^{f} r_{i j}^{c r} \\
& +\sum_{n \in \Omega^{l b}} c e_{n}^{p} \sum_{i \in \Omega^{e c}} \sum_{j=1}^{n_{i}} L S_{n}^{i j} \mu_{i j} r_{i j}^{p r}
\end{aligned}
$$

Where,

$$
\begin{aligned}
& C_{i}^{L}=8760 C_{i}^{H L} \\
& C_{i}^{H L}=k^{L} P_{i}^{L} C^{L} \\
& P_{i}^{L}=R_{i}\left|I_{i}\right|^{2} \\
& I_{i}=P_{i} /\left|V_{i}\right| \\
& R_{i}=\ell_{i} r_{i} /\left(\underline{n_{i}}+n_{i}\right) \\
& C_{i j}^{M}=\ell_{i} k_{i j} \underline{C_{i j}^{M}} \\
& C_{i j}^{p r}=\ell_{i} k_{i j}^{p r} \underline{C_{i j}^{p r}} \\
& k_{i j}^{p r}=\mu_{i j} / \underline{\mu_{i j}} \\
& C_{i j}^{c r}=\ell_{i} k_{i j}^{c r} \underline{C_{i j}^{c r}} \\
& C_{i j}^{p r}=\underline{\underline{C_{i j}^{p r}}} \underline{\mu_{i j}} \underline{r_{i j}^{p r}} \\
& C_{i j}^{c r}=\underline{\underline{C_{i j}^{c r}}} \underline{\lambda_{i j}^{f}} \underline{r_{i j}^{c r}} \\
& v_{i j}=\left\{\begin{array}{l}
1 \quad \text { for } n_{i j}^{l 0} \leq n_{i j}^{r l}-T \\
C_{i j}^{R} /\left(C_{i j}^{M}+C_{i j}^{p r}+C_{i j}^{c r}\right) \quad \text { otherwise }
\end{array}\right.
\end{aligned}
$$


Subject to:

$$
\begin{aligned}
& G_{n}=D_{n}+\sum_{m \in \Omega^{b}} P_{n m} \quad \forall n \in \Omega^{b}, m \neq n \\
& P_{i}= Y_{i} \Delta \theta_{i} \\
& Y_{i}= \ell_{i} \gamma_{i}\left(\underline{n_{i}}+n_{i}\right) \\
& P_{n m}^{i j}= \sum_{f \in \Omega^{g b}} \hat{a}_{f, n m}^{i j} G_{f}+\sum_{q \in \Omega^{l b}} \hat{b}_{q, n m}^{i j}\left(D_{q}-L S_{q}^{i j}\right) \\
&\left|P_{i}\right| \leq \overline{P_{i}} \quad \forall i \in \Omega^{c} \\
&\left|P_{n m}^{i j}\right| \leq \overline{P_{n m}} \forall n, m \in \Omega^{b}, n \neq m, i \in \Omega^{c}, \\
& j=1, \ldots, \underline{n_{i}} \\
& 0 \leq n_{i} \leq \overline{n_{i}}-\underline{n_{i}} \quad \forall i \in \Omega^{c} \\
& 0 \leq n_{i}^{s} \leq \overline{n_{i}}-\underline{n_{i}} \quad \forall i \in \Omega^{s} \\
& 0 \leq S_{n}^{i j} \leq D_{n} \quad \forall n \in \Omega^{l b}, i \in \Omega^{c}, j=1, \ldots, \underline{n_{i}} \\
& 1 \leq k_{i j} \leq k_{i j}^{\mathrm{Max}} \forall i \in \Omega^{e c}, j=1,2, \ldots, \underline{n_{i}}
\end{aligned}
$$

The first and second terms of equation (1) represent the construction costs of new transmission lines and substations, respectively. The third term describes the power losses cost of the transmission network. This cost plays an important role in the TNEP, because it efficiently affects the network configuration [20] through variables $n_{i}$, in (6), and $\Delta \theta_{i}$, in (15). The active power losses of each corridor $\left(P_{i}{ }^{L}\right)$ are computed using (4)-(6). Also, hourly and annual costs of power losses for each corridor are determined by (3) and (2), respectively (the calculation method of losses coefficient $\left(k^{L}\right)$ was explained in [20]). The fourth term describes the maintenance, and preventive and corrective repair costs of the transmission network that is calculated using (7)-(12). Maintenance includes activities that are done in regular intervals to prevent appearance of defect in transmission line during maintenance period (times shorter than planned outage durations). Preventive repair involves required actions that are performed during the planned outages in regular intervals to remove the line defects before it fails. Corrective repairs are necessary actions carried out during the forced outages in order to restore the failed line. Also, the fifth and sixth terms show the cost of load curtailment (the calculation method of load shedding has been described in [19]) and energy not supplied (ENS) due to the forced outage of a single transmission line, respectively. Finally, the seventh term indicates the cost of energy not supplied due to the planned (scheduled) outage of a single line. These terms depend on the optimization variables of $L S_{n}^{i j}$ and $k_{i j}$ in that their relationship with $k_{i j}$ can be justified using dependences of $\lambda_{i j}^{f}$ and $\lambda_{i j}^{t}$ on $\lambda_{m i j}^{f}$ and $\lambda_{m i j}^{t}$ via (52) and (53), and using coherence of $\lambda_{m i j}^{f}$ and $\lambda_{m i j}^{t}$ with $k_{i j}$ through (26) and (27) beside relationships of $\mu_{i j}, r_{i j}^{c r}$, and $r_{i j}^{p r}$ with $k_{i j}$ ((31), (39), and (47)). Equations (7), (8), and (10) declare that the total maintenance cost, as well as preventive and corrective repair costs are coefficients of their fixed values (refer to equations (5) and (6) of [19]). These costs depend on the optimization variable of $k_{i j}$. In simple terms, preventive repair cost is a function of $k_{i j}$, due to the relationship between $k_{i j}^{p r}$ and $\mu_{i j}$ through (9) and coherence of $\mu_{i j}$ with $k_{i j}$ via (31). Equation (9) explains the relation between preventive repair cost coefficient and the planned outage rate. This relation is driven by replacing $\chi_{(i j)}=\mu_{i j} / \mu_{i j}$ in (31) of [19] (see Subsection B for more details). Also, the corrective repair cost is relative to variable $k_{i j}$ via (10), (26), and (49). Equations (11) and (12) show that the fixed preventive and corrective repair costs are equal to their hourly values multiplied by basic number and duration of repairs. Equation (13) expresses that the replacement of existing lines with new ones is not necessary if the initial operation periods of the lines are less than or equal to their regular lifetimes minus the planning horizon year. The first, second, and third terms of (1) are similar to the first, second, and fourth terms of equation (1) in [19], respectively. The new formulation does not include the fourth term of the objective function (1) in [19]. Instead, this term is considered here, in (13), as a secondary factor. In other words, in [19], the replacement cost depended on the lines' life expectancies, while in the present paper, this cost is considered to be constant, because optimization variables of life expectancies were not considered in the present model. Also, the fifth term of (1) in the previous paper was extended to the fourth term of the new objective function. Although the maintenance cost is considered here, it is different from the maintenance cost in [19]. According to (7), the new maintenance cost is a function of the independent optimization variables of $k_{i j}$, while the maintenance cost in the previous research was a function of life expectancies. Moreover, in [19], repair cost was considered to be a function of life expectancies, while in the current research, it is classified as preventive and corrective repairs, whereby each of them individually depends on $k_{i j}$. In addition, the sixth term of the previous objective function is now replaced by three new terms (the fifth, sixth, and seventh terms). In other words, in [19], the reliability cost was related only to the lines' permanent forced and planned outage rates, while in this paper, the transient forced outage rate, as well as the forced and planned outage durations, were added to the objective function. Lastly, the seventh term of (1) in [19] is ignored in the present TNEP model, because it depends on the lines' life expectancies and reflects the economic effects of maintenance on TNEP. This paper focuses more on the reliability aspects of maintenance. The expansion plan must satisfy all of the constraints (14)-(23) with minimum maintenance and repair costs, and maximum reliability. Equation (14) indicates the DC power flow balance for each bus (node). Equations (15) and (17) are the DC power flow to transmission lines when no line outage occurs (normal condition) and a line fails (contingency state), respectively. In (17), $\hat{a}_{f, n m}^{i j}$ and $\hat{b}_{q, n m}^{i j}$ are determined by the DC power flow [19]. Equations (18) and (19) explain the power flow limits on the transmission lines in normal and contingency states. Equations (20)-(23) show rightof-way constraint, maximum number of new substations, maximum load shedding, and maintenance cost coefficient limitation, respectively. 


\section{A. Effect of the Maintenance Cost Coefficient $\left(k_{\mathrm{ij}}\right)$ on the Forced Outage Rates}

Equation (24) (curve of forced outages) describes mathematically the relationship between $\zeta_{i j}$ and $k_{i j}$ [19].

$$
\zeta_{i j}=\alpha_{i j}+\left(T / n_{i j}^{r l}\right)-\eta\left(1-\alpha_{i j}\right)\left(\beta_{i j}\right)^{1 / m_{i j}}\left(k_{i j}-1\right)^{1 / m_{i j}}
$$

where, $\zeta_{i j}=\lambda_{m i j} / \underline{\lambda_{i j}}, \alpha_{i j}=n_{i j}^{l 0} / n_{i j}^{r l}, \beta_{i j}=\underline{\underline{C_{i j}^{M}} / C_{i j}^{r}}$ and $\eta$ is a coefficient to exhibit variation of the curve's slope. $m_{i j}$ can be calculated using (25) [19].

$$
m_{i j}=M_{i j}-\left(M_{i j}-1\right) \alpha_{i j}{ }^{1 / 2}
$$

To apply (24) to describe the relationship between a line's permanent forced outage rate coefficient and $k_{i j}, \zeta_{i j}$ and $\beta_{i j}$ need to be replaced by $\zeta_{i j}^{f}$ and $\beta_{i j}^{f}$, respectively.

$$
\begin{aligned}
\zeta_{i j}^{f}= & \alpha_{i j}+T / n_{i j}^{r l}-\eta\left(1-\alpha_{i j}\right)\left(\beta_{i j}^{f}\right)^{1 / m_{i j}} \\
& \times\left(k_{i j}-1\right)^{1 / m_{i j}} \quad k_{i j} \geq 1
\end{aligned}
$$

This equation is known as the "curve of permanent forced outage," where $\eta=0.5, \zeta_{i j}^{f}=\lambda_{m i j}^{f} / \underline{\lambda_{i j}^{f}}$, and $\beta_{i j}^{f}=\underline{\underline{C_{i j}^{M}} / C_{i j}^{c r}}$. Permanent outages are those that require component repair in order to restore the component to service. Also, if $\zeta_{\mathrm{ij}}$ and $\beta_{\mathrm{ij}}$ are defined as $\zeta_{i j}^{t}$ and $\beta_{i j}^{t}$, (24) can be written as (27).

$$
\begin{aligned}
\zeta_{i j}^{t}= & \alpha_{i j}+T / n_{i j}^{r l}-\eta\left(1-\alpha_{i j}\right)\left(\beta_{i j}^{t}\right)^{1 / m_{i j}} \\
& \times\left(k_{i j}-1\right)^{1 / m_{i j}} \quad k_{i j} \geq 1
\end{aligned}
$$

This equation is the "curve of transient forced outage," where $\zeta_{i j}^{t}=\lambda_{m i j}^{t} / \underline{\lambda_{i j}^{t}}$ and $\beta_{i j}^{t}=\underline{\underline{C_{i j}^{M}} / C_{i j}^{p r}}$. Transient outages are those that are not permanent. These include both automatic and manual reclosing. To calculate the maximum value of $k_{i j}, \zeta_{i j}^{f}$ and $\zeta_{i j}^{t}$ have to be equal to zero in (26) and (27), respectively. Then, their minimum amounts have to be selected, because negative values of $\zeta_{i j}^{f}$ or $\zeta_{i j}^{t}$ are not permitted.

$$
\begin{aligned}
& k_{i j}^{\mathrm{Max} 1}=1+\left(1 / \beta_{i j}^{f}\right)\left[\left(\alpha_{i j}+T / n_{i j}^{r l}\right) / \eta\left(1-\alpha_{i j}\right)\right]^{m_{i j}} \\
& k_{i j}^{\mathrm{Max} 2}=1+\left(1 / \beta_{i j}^{t}\right)\left[\left(\alpha_{i j}+T / n_{i j}^{r l}\right) / \eta\left(1-\alpha_{i j}\right)\right]^{m_{i j}} \\
& k_{i j}^{\mathrm{Max}}=\min \left\{k_{i j}^{\mathrm{Max} 1}, k_{i j}^{\mathrm{Max} 2}\right\}
\end{aligned}
$$

In this way, the transient forced outage rate was correlated to the maintenance cost coefficient through (27), and for $k_{i j}$, a maximum value was calculated by (28)-(30), while in [19], these equations have not been formulated.

\section{B. Effect of $k_{\mathrm{ij}}$ on the Planned Outage Rate $\left(\mu_{\mathrm{ij}}\right)$}

Generally, repairs can be divided into preventive and corrective. Preventive repair actions are carried out to prevent the forced outage of lines. In simple terms, these efforts are required before the equipment fails. Corrective repairs are performed to repair the failed elements and to restore the component to service. In the curve of MTTR (refer to equation (28) in [19]), $\chi_{i j}$ is related to preventive repairs (scheduled outages). Preventive repair activities are carried out at regular intervals (certain
MTTRs). To formulate (31) and to show the relationship between the number of preventive repairs (planned outage rates) and maintenance, it is necessary, for $\beta_{i j}$ in (28) of [19], to be written as $\beta_{i j}^{t}$ and $\chi_{i j}$ to be replaced by $\mu_{i j} / \mu_{i j}\left(\varpi_{1}=7\right.$, $\varpi_{2}=\varepsilon=a=2$, and $b=4$ ).

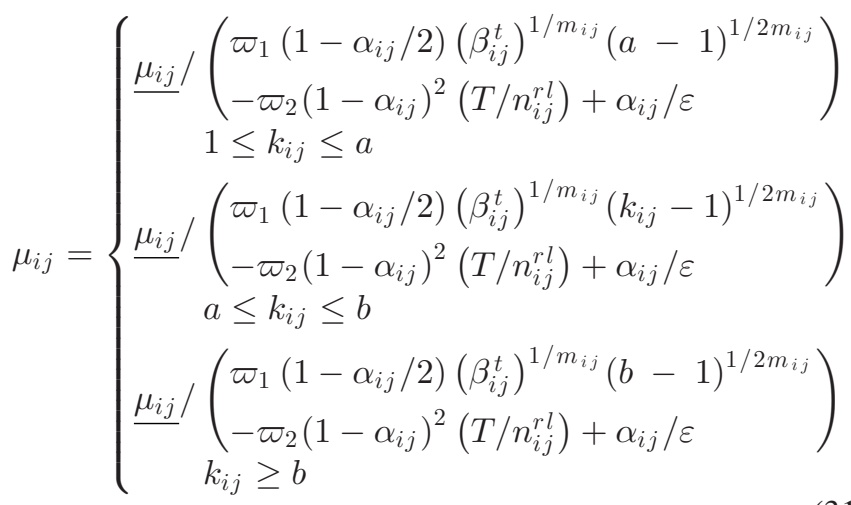

The reason for this replacement is that $\mu_{i j}=8760 / \tau_{i j}$ and $\mu_{i j}=8760 / \tau_{i j}$, where $\chi_{(i j)}=\tau_{i j} / \tau_{i j}$ (see (29) and (30) of [19] $\overline{\text { for }}$ more information).

\section{Effect of $k_{\mathrm{ij}}$ on the Outage Durations}

Transmission equipment outages can be categorized as forced or planned outages. It is assumed that forced outages are those that happen due to network faults or element failures. Planned outages are those that have been arranged for preventive repairs at regular intervals. Forced outages can be classified as permanent or transient. Permanent forced outages include failed transmission lines that can be restored by corrective repairs. Transient forced outages, on the other hand, involve only transmission lines that exit from the network by automatic or manual reclosing due to a fault in the system. For transient outages, the outage duration is very short and can be ignored in reliability calculations. Instead, permanent forced and planned outages are of considerable duration due to the time required for corrective and preventive repairs. Accordingly, outage durations consist of forced outages due to corrective repairs and planned outages due to preventive repairs. Maintenance actions affect both outage durations and outage rates (refer to Subsections A and B). It is clear that if maintenance efforts increase, outage durations decrease. To show this fact, $\beta_{i j}^{f}$ from (26) is written in terms of $k_{i j}$ as follows.

$\beta_{i j}^{f}=\left[\left(\alpha_{i j}+\left(T / n_{i j}^{r l}\right)-\zeta_{i j}^{f}\right) / \eta\left(1-\alpha_{i j}\right)\right]^{m_{i j}} 1 /\left(k_{i j}-1\right)$

By replacing $\underline{C_{i j}^{c r}}$ from (12) in $\beta_{i j}^{f}=\underline{C_{i j}^{M}} / C_{i j}^{c r}$ :

$$
\beta_{i j}^{f}=\underline{\underline{C_{i j}^{M}}} \underline{\underline{\lambda_{i j}^{f}}} \underline{\underline{r_{i j}^{c r}}} / \underline{C_{i j}^{c r}}
$$

Equation (34) results from comparing (32) and (33), where $r_{i j}^{c r} \propto r_{i j}^{c r} \cdot \eta_{1 i j}$ is a coefficient that replaces $\eta$ in order to show 
the proportion between $r_{i j}^{c r}$ and $\underline{r_{i j}^{c r}}$.

$$
\begin{aligned}
& r_{i j}^{c r}= \\
& \left\{\begin{array}{l}
\left(\frac{C_{i j}^{c r}}{\overline{C_{i j}^{M}}}\right)\left[\frac{\alpha_{i j}+\left(T / n_{i j}^{r l}\right)-\zeta_{i j}^{f}}{\eta_{1 i j}\left(1-\alpha_{i j}\right)}\right]^{m_{i j}} \frac{1}{\frac{\lambda_{i j}^{f}\left(k_{i j}-1\right)}{1}} k_{i j} \geq 2 \\
\underline{r_{i j}^{c r}}
\end{array}\right.
\end{aligned}
$$

For $k_{i j}=2, r_{i j}^{c r}$ is equal to $r_{i j}^{c r}$. Therefore, $\eta_{1 i j}$ can be written as follows:

$$
\begin{aligned}
\eta_{1 i j}= & \left(\underline{C_{i j}^{c r} /} \underline{\underline{C_{i j}^{M}}}\right)^{1 / m_{i j}}\left[\frac{\alpha_{i j}+\left(T / n_{i j}^{r l}\right)-\zeta_{i j}^{f}}{\left(1-\alpha_{i j}\right)}\right] \\
& \times\left(1 / \underline{r_{i j}^{c r} \lambda_{i j}^{f}}\right)^{1 / m_{i j}}
\end{aligned}
$$

Replacing $\zeta_{i j}^{f}$ from (26) in (34) and (35), respectively, yields (36) and (37).

$$
\begin{array}{rlrl}
r_{i j}^{c r} & =\left(\eta / \eta_{1 i j}\right)^{m_{i j}} \frac{r_{i j}^{c r}}{} & & k_{i j} \geq 2 \\
\eta_{1 i j} & =\eta\left(k_{i j}-1\right)^{1 / m_{i j}} & k_{i j} \geq 2
\end{array}
$$

If (37) is replaced in (36) and the result is included in (34), then $(38)$ is obtained.

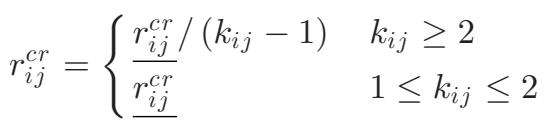

Similar to $\chi_{i j}$ in (28) of [19], which was fixed for larger maintenance cost coefficients $\left(k_{i j} \geq b\right), r_{i j}^{c r}$ does not vary for $k_{i j} \geq b$ because, in this situation, the maintenance cost has become equal to the repair expenditure and, therefore, further maintenance cannot affect corrective repair duration. Thus, (38) can be presented as follows:

$$
r_{i j}^{c r}= \begin{cases}\frac{r_{i j}^{c r} /(b-1)}{r_{i j}^{c r}} /\left(k_{i j}-1\right) & 2 \leq k_{i j} \leq b \\ \frac{r_{i j}^{c r}}{} & 1 \leq k_{i j} \leq 2\end{cases}
$$

This relation shows the effect of $k_{i j}$ on the permanent forced outage duration $\left(r_{i j}^{c r}\right)$. Also, if $\beta_{i j}^{t}$ from (27) is written in terms of $k_{i j}$, the result is (40):

$$
\beta_{i j}^{t}=\left[\left(\alpha_{i j}+\left(T / n_{i j}^{r l}\right)-\zeta_{i j}^{t}\right) / \eta\left(1-\alpha_{i j}\right)\right]^{m_{i j}} 1 /\left(k_{i j}-1\right)
$$

Replacing $\underline{\underline{C_{i j}^{p r}}}$ from (11) in $\beta_{i j}^{t}=\underline{\underline{C_{i j}^{M}} /} \underline{\underline{C_{i j}^{p r}}}$, yields:

$$
\beta_{i j}^{t}=\underline{\underline{C_{i j}^{M}}} \underline{\underline{\mu_{i j}}} r_{i j}^{p r} / \underline{C_{i j}^{p r}}
$$

Therefore, $r_{i j}^{p r}$ can be written in terms of $k_{i j}$ to show the maintenance effect on the scheduled outage duration (h).

$r_{i j}^{p r}=$

$\left\{\begin{array}{l}\left(\frac{C_{i j}^{p r}}{\overline{C_{i j}^{M}}}\right)\left[\frac{\alpha_{i j}+\left(T / n_{i j}^{r l}\right)-\zeta_{i j}^{t}}{\eta_{2 i j}\left(1-\alpha_{i j}\right)}\right]^{m_{i j}} \frac{1}{\frac{\mu_{i j}\left(k_{i j}-1\right)}{\bar{r}}} \quad k_{i j} \geq 2 \\ 1 \leq k_{i j} \leq 2\end{array}\right.$

Given that for $k_{i j}=2, r_{i j}^{p r}=r_{i j}^{p r}$, (43) can be obtained. $\eta_{2 i j}$ is a coefficient to show the proportion of $r_{i j}^{p r}$ to $r_{i j}^{p r}$.

$$
\begin{aligned}
\eta_{2 i j}= & \left(\frac{C_{i j}^{p r}}{\underline{C_{i j}^{M}}}\right)^{\frac{1}{m_{i j}}}\left[\left(\alpha_{i j}+\left(T / n_{i j}^{r l}\right)-\zeta_{i j}^{t}\right) /\left(1-\alpha_{i j}\right)\right] \\
& \times\left(\frac{1}{r_{i j}^{p r}} \underline{\mu_{i j}}\right)^{\frac{1}{m_{i j}}}
\end{aligned}
$$

If $\zeta_{i j}^{t}$ from (27) is replaced in (42) and (43), respectively, (44) and (45) can be deduced.

$$
\begin{aligned}
r_{i j}^{p r} & =\left(\eta / \eta_{2 i j}\right)^{m_{i j}} \frac{r_{i j}^{p r}}{} & & k_{i j} \geq 2 \\
\eta_{2 i j} & =\eta\left(k_{i j}-1\right)^{1 / m_{i j}} & & k_{i j} \geq 2
\end{aligned}
$$

By replacing (45) in (44) and inserting the results in (42), the following equation is provided.

$$
r_{i j}^{p r}= \begin{cases}\frac{r_{i j}^{p r} /\left(k_{i j}-1\right)}{r_{i j}^{p r}} & k_{i j} \geq 2 \\ \underline{ } & 1 \leq k_{i j} \leq 2\end{cases}
$$

Similar to (39), the duration of preventive repairs $\left(r_{i j}^{p r}\right)$ is fixed for larger amounts of maintenance cost $\left(k_{i j} \geq b\right)$. Accordingly, (46) can be written as (47). Here, the relationships of permanent and planned outage durations with maintenance cost were formulated, while these equations have not been presented in [19].

$$
r_{i j}^{p r}= \begin{cases}\frac{r_{i j}^{p r} /(b-1)}{r_{i j}^{p r}} /\left(k_{i j}-1\right) & 2 \leq k_{i j} \leq b \\ \frac{r_{i j}^{p r}}{} & 1 \leq k_{i j} \leq 2\end{cases}
$$

\section{Effect of the Corrective Repair Cost Coefficient $\left(k_{\mathrm{ij}}^{c r}\right)$ on the Permanent Forced Outage Rate $\left(\lambda_{m i j}^{f}\right)$}

In addition to preventive repairs, specified corrective repair activities are required to restore the failed lines during their functioning lives. To perform these activities, a fixed corrective repair cost is essential. Due to the explanations given in Subsection $\mathrm{E}$ of [19], it can be concluded that the number of corrective repairs (permanent forced outage rate) may decrease if the maintenance cost increases. Also, the total corrective repair cost is reduced as the fixed corrective repair cost diminishes. This fact can be described analytically as follows:

$$
C_{i j}^{c r}=\underline{\ell_{i}} \underline{C_{i j}^{c r}} /\left(\lambda_{m i j}^{f} / \underline{\lambda_{i j}^{f}}\right)
$$


Equation (49) can be deduced by comparing (48) to (10).

$$
\zeta_{i j}^{f}=k_{i j}^{c r}
$$

The effect of corrective repair cost on permanent forced outage rate ((48) and (49)) has not been considered in [19].

\section{E. Effect of the Line Loading on the Forced Outage Rates}

Equation (50) states the forced outage rate of transmission line in terms of the line loading [19].

$$
\begin{aligned}
& \lambda_{i j}=\rho_{i j}\left(\underline{\lambda_{i j}}-\lambda_{m i j}\right)+\lambda_{m i j} \\
& \rho_{i j}=P_{i j} / \overline{P_{i j}}
\end{aligned}
$$

To consider effect of the line loading on the permanent forced outage rate, $\lambda_{i j}, \lambda_{i j}$ and $\lambda_{m i j}$ can be replaced by $\lambda_{i j}^{f}, \lambda_{i j}^{f}$ and $\lambda_{m i j}^{f}$, respectively.

$$
\lambda_{i j}^{f}=\rho_{i j}\left(\underline{\lambda_{i j}^{f}}-\lambda_{m i j}^{f}\right)+\lambda_{m i j}^{f}
$$

Also, if $\lambda_{i j}, \lambda_{i j}$ and $\lambda_{m i j}$ are defined as $\lambda_{i j}^{t}, \lambda_{i j}^{t}$ and $\lambda_{m i j}^{t}$, (53) is resulted. This equation describes effect of the line loading on the transient forced outage rate.

$$
\left.\lambda_{i j}^{t}=\rho_{i j} \underline{\left(\lambda_{i j}^{t}\right.}-\lambda_{m i j}^{t}\right)+\lambda_{m i j}^{t}
$$

It should be noted that the effect of lines' loading on transient forced outage rate was neglected in [19].

\section{SOlution Method}

In the present study, the goal is to minimize the objective function (1) using DCGA [21], while the principle of genetic algorithm (GA) is to maximize the fitness function. To do so, (54) maps the equation (1) into the fitness function.

$$
\text { Fitness }=A / F
$$

Where $A=10^{13}$ is a system-dependent constant. Constant $A$ is used to prevent the fitness from obtaining too small values.

In the first step $(t=0)$, the total demand on each bus at the end of the planning horizon $\left(D_{n}\right)$ is determined according to the load growth factor of $10 \%(L G F=0.1)$ [20] using (55).

$$
D_{n}=D_{n}^{0}(1+L G F)^{T}
$$

Equation (56), considering constraints (57) and (58) (economic load dispatch (ELD) problem), is solved using the quadprog function, in order to obtain the total generation of each bus at the end of planning horizon $\left(G_{n}\right)$.

$$
\min \sum_{n \in \Omega^{g b}}\left(c_{1 n} G_{n}^{2}+c_{2 n} G_{n}+c_{3 n}\right)
$$

Subject to:

$$
\begin{aligned}
\sum_{n \in \Omega^{g b}} G_{n} & =\sum_{n \in \Omega^{l b}} D_{n} \\
G_{n}^{\min } & \leq G_{n} \leq G_{n}^{\max } \quad \forall n \in \Omega^{g b}
\end{aligned}
$$

Where, $c_{1 n}\left(\$ / \mathrm{MW}^{2} \mathrm{~h}\right), c_{2 n}(\$ / \mathrm{MWh})$, and $c_{3 n}(\$ / \mathrm{h})$ are cost coefficients of the generating units on bus $n$. Equations (57) and (58) define the balance between generation and demand in the network and the buses' generation limits, respectively. quadprog is a function in the optimization toolbox of MATLAB that can be applied to minimize quadratic constrained problems including continuous variables. Then an initial population with $d$ chromosomes $(d=10)$ is constructed randomly as (59) when constraints (20) and (21) are satisfied.

$$
X=\left[\begin{array}{llllll}
X_{1} & X_{2} & \ldots & X_{i} & \ldots & X_{d}
\end{array}\right]^{\text {Transpose }}
$$

In (59), $X_{d}$ is the $d$ th chromosome of the population $X$. This vector consists of $N\left(\left|\Omega^{c}\right|+\left|\Omega^{s}\right|\right.$ ) integer numbers (problem variables) such as:

$$
X_{d}=\left[n_{1}, n_{2}, \ldots, n_{i}, \ldots, n_{\left|\Omega^{c}\right|}, n_{1}^{s}, n_{2}^{s}, \ldots, n_{i}^{s}, \ldots, n_{\left|\Omega^{s}\right|}^{s}\right]
$$

where, $n_{i}$ and $n_{i}^{s}$ indicate the number of new circuits and new substations in corridor $i$, respectively.

$$
\begin{array}{ll}
n_{i}=\left\{0,1, \ldots, \overline{n_{i}}-\underline{n_{i}}\right\} & \forall i \in \Omega^{c} \\
n_{i}^{s}=\left\{0,1, \ldots, \overline{n_{i}}-\underline{n_{i}}\right\} & \forall i \in \Omega^{s}
\end{array}
$$

Equation (63) describes a typical chromosome for a network with 15 corridors.

$$
X_{i}=[1,2,2,0,0,1,0,2,1,2,0,1,0,1,0]
$$

$X_{\mathrm{i}}$ proposes one new transmission circuit for corridors 1,6 , 9, 12, and 14, two new transmission circuits for corridors 2,3 , 8 , and 10, and no new transmission circuits for corridors 4, 5, 7, 11, 13, and 15. Afterward, Equations (4) and (5) are calculated considering constraints (14) and (15) using DC power flow after determination of (6). If (18) is satisfied, (64) considering constraints (17), (19) and (22) is solved using the fmincon function to determine the load shedding of each bus in contingency states (line outages). fmincon is a function in the optimization toolbox of MATLAB, which can be used for minimizing constrained nonlinear multivariable problems.

$$
\min \sum_{n \in \Omega^{l b}} L S_{n}^{i j}
$$

In addition, the following equation, while satisfying constraint (23), is minimized using the fmincon function to calculate $k_{i j}$.

$$
\begin{aligned}
& \min \sum_{i \in \Omega^{e c}} \sum_{j=1}^{\underline{n_{i}}}\left[C_{i j}^{M}+C_{i j}^{p r}+C_{i j}^{c r}\right]+\sum_{n \in \Omega^{l b}} V O L L_{n} \\
& \times \sum_{i \in \Omega^{e c}} \sum_{j=1}^{\underline{n_{i}}} L S_{n}^{i j} \lambda_{i j}^{t}+\sum_{n \in \Omega^{l b}} c e_{n}^{f} \sum_{i \in \Omega^{e c}} \sum_{j=1}^{\underline{n_{i}}} L S_{n}^{i j} \lambda_{i j}^{f} r_{i j}^{c r} \\
& +\sum_{n \in \Omega^{l b}} c e_{n}^{p} \sum_{i \in \Omega^{e c}} \sum_{j=1}^{\underline{n_{i}}} L S_{n}^{i j} \mu_{i j} r_{i j}^{p r}
\end{aligned}
$$

Then, (2), (3), and (7)-(13) are calculated, and consequently, objective function (1) is determined. After that, the selection operator selects the chromosomes in the population that are more fit for reproduction. The reproduction operator reproduces each chromosome in proportion to the value of its fitness function (Eq. (54)). After the pairs of parent chromosomes have 


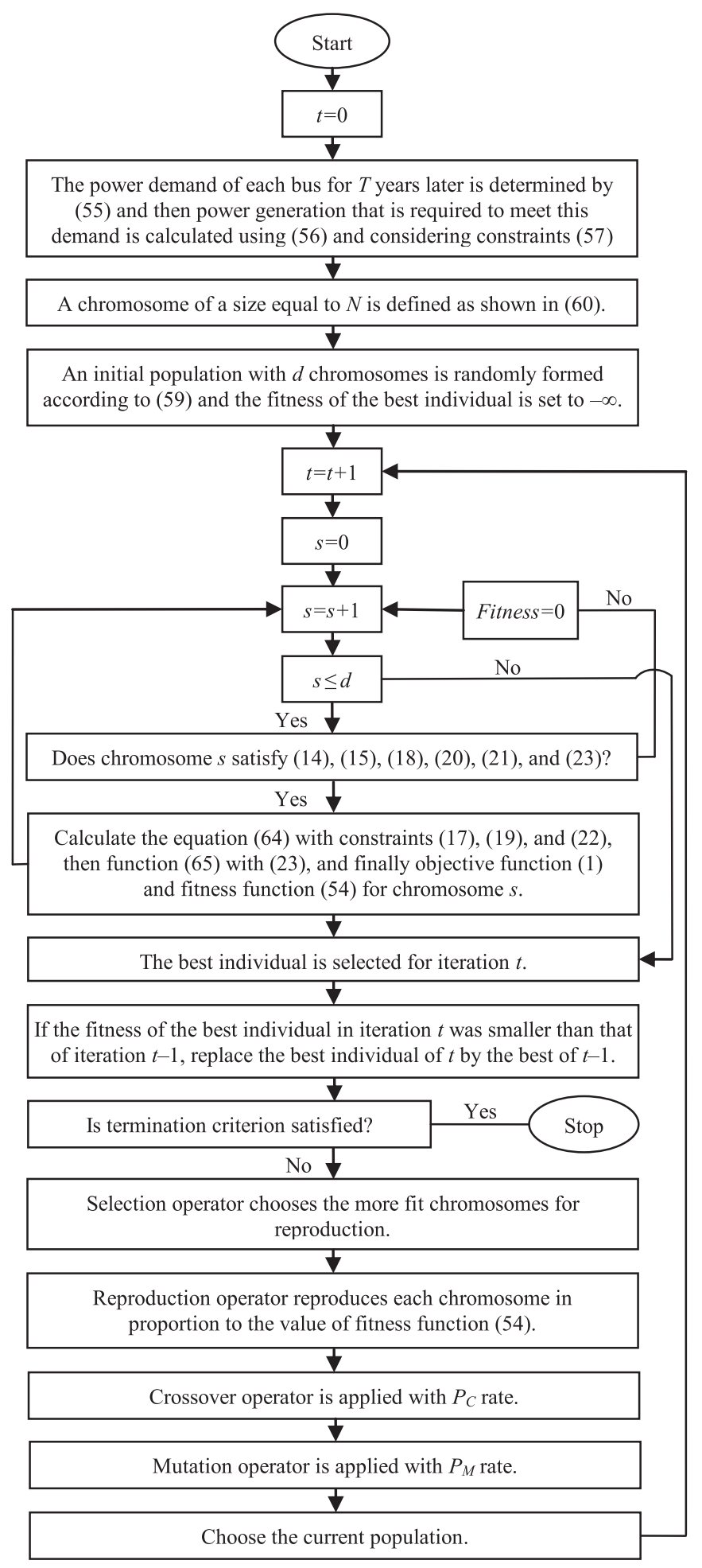

Fig. 1. Flowchart of the proposed method.

been selected, the crossover operator chooses an even number of chromosomes at random with a probability of $0.9\left(P_{\mathrm{C}}=\right.$ 0.9). Random positions (between two integer numbers) are chosen for each pair of the selected chromosomes, and then the two chromosomes of each pair swap their variables. Each chromosome resulting from the crossover operation is then subject
TABLE I

VOLL AND COST OF ENERGY NOT SUPPLIED FOR IEEE RTS

\begin{tabular}{lccccccc}
\hline \hline Bus & $\begin{array}{c}\text { VOL } L_{n} \\
(\$ / \mathrm{MW})\end{array}$ & $\begin{array}{c}c e_{n}^{p} \\
(\$ / \mathrm{MWh})\end{array}$ & $\begin{array}{c}c e_{n}^{f} \\
(\$ / \mathrm{MWh})\end{array}$ & Bus & $V O L L_{n}$ & $c e_{n}^{p}$ & $c e_{n}^{f}$ \\
\hline 1 & 950 & 380 & 3800 & 10 & 1700 & 680 & 6800 \\
2 & 850 & 340 & 3400 & 13 & 2100 & 840 & 8400 \\
3 & 1600 & 640 & 6400 & 14 & 1700 & 680 & 6800 \\
4 & 650 & 260 & 2600 & 15 & 2775 & 1110 & 11100 \\
5 & 625 & 250 & 2500 & 16 & 875 & 350 & 3500 \\
6 & 1200 & 480 & 4800 & 18 & 2925 & 1170 & 11700 \\
7 & 1100 & 440 & 4400 & 19 & 1625 & 650 & 6500 \\
8 & 1500 & 600 & 6000 & 20 & 1125 & 450 & 4500 \\
9 & 1550 & 620 & 6200 & - & - & - & - \\
\hline \hline
\end{tabular}

to the mutation operator in the final step of forming the new generation. This operator selects a few existing variables in the chromosome and then changes their values at random with a probability of $0.1\left(P_{\mathrm{M}}=0.1\right)$. It should be mentioned that in this process, (20) and (21) must be satisfied. After mutation, the production of the new generation is complete, and the process can begin all over again with the evaluation of (54) for each chromosome. The process continues and is terminated either by setting a target value for the fitness function to be achieved, or by setting a definite number of generations (iterations, $t$ ) to be produced. The flowchart of the proposed method is shown in Fig. 1.

\section{Simulation Results}

The IEEE RTS [22] and IEEE 30-bus test system were used to demonstrate the proposed TNEP formulation. The maximum number of circuits in each corridor $\left(\overline{n_{i}}\right)$, the regular lifetime $\left(n_{i}^{r l}\right)$ of all transmission lines, and the planning horizon $(T)$ are considered to be 2, 30 years, and 15 years for both case study systems.

\section{A. IEEE Reliability Test System (IEEE RTS)}

This 24-bus network contains 17 load busses (17 load shedding variables), 29 existing lines (29 maintenance cost coefficients), and 141 transmission corridors $\left(\left|\Omega^{c}\right|=136\right.$ and $\left|\Omega^{s}\right|=$ 5) at two voltage levels: $138 \mathrm{kV}$ and $230 \mathrm{kV}$. All data of this test system is presented in [22]. Also, the initial operation period $\left(n_{i j}^{l 0}\right)$, number and duration of the planned outages for the existing lines $\left(\underline{\mu_{i j}}\right.$ and $\left.r_{i j}^{p r}\right)$, VOLL, and cost of one MWh energy not supplied for this network are listed in Tables I and II.

Three scenarios are considered to study the proposed model. In Scenario 1, the TNEP problem was solved without considering maintenance. In Scenario 2, the reliability effects of maintenance and line loading were considered. In Scenario 3, results of Scenarios 1 and 2 were compared with the simulation results of [19] for RTS.

1) Scenario 1: The goal was to solve the TNEP problem considering only fixed repair costs, network losses, and transmission system reliability without any maintenance and reliability effects of line loading $\left(k_{i j}=0, k_{i j}^{p r}=k_{i j}^{c r}=\rho_{i j}=1\right)$. The proposed idea was tested on the IEEE RTS. New lines that 
TABLE II

OPERATION PERIODS, AND PLANNED OUTAGE RATES AND DURATIONS FOR IEEE RTS

\begin{tabular}{|c|c|c|c|c|c|c|c|}
\hline Corr. & $\begin{array}{c}n_{i j}^{l 0} \\
\text { (year) }\end{array}$ & $\frac{\mu_{i j}}{(1 / \text { year })}$ & $\frac{r_{i j}^{p r}}{(\mathrm{~h})}$ & Corr. & $\begin{array}{c}n_{i j}^{l 0} \\
\text { (year) }\end{array}$ & $\frac{\mu_{i j}}{(1 / \text { year })}$ & $\frac{r_{i j}^{p r}}{(\mathrm{~h})}$ \\
\hline $1-2$ & 10 & 2.6 & 8 & $12-23$ & 20 & 1.1 & 5.5 \\
\hline $1-3$ & 15 & 1.7 & 5 & $13-23$ & 15 & 1 & 5.5 \\
\hline $1-5$ & 15 & 0.8 & 5 & $14-16$ & 15 & 0.5 & 5.5 \\
\hline $2-4$ & 15 & 1 & 5 & $15-16$ & 16 & 0.3 & 5.5 \\
\hline $2-6$ & 5 & 1.5 & 5 & $15-21$ & 14 & 0.6 & 5.5 \\
\hline $3-9$ & 12 & 1 & 5 & $15-24$ & 15 & 0.6 & 5.5 \\
\hline $4-9$ & 20 & 0.9 & 5 & $16-17$ & 13 & 0.4 & 5.5 \\
\hline $5-10$ & 15 & 0.8 & 5 & $16-19$ & 8 & 0.4 & 5.5 \\
\hline $6-10$ & 10 & 2.6 & 17.5 & $17-18$ & 5 & 0.3 & 5.5 \\
\hline $7-8$ & 15 & 0.5 & 5 & $17-22$ & 11 & 1.2 & 5.5 \\
\hline $8-9$ & 12 & 1.4 & 5 & $18-21$ & 9 & 0.4 & 5.5 \\
\hline $8-10$ & 15 & 1.4 & 5 & 19-20 & 14 & 0.5 & 5.5 \\
\hline $11-13$ & 12 & 0.6 & 5.5 & $20-23$ & 17 & 0.4 & 5.5 \\
\hline $11-14$ & 15 & 0.5 & 5.5 & $21-22$ & 18 & 0.8 & 5.5 \\
\hline $12-13$ & 15 & 0.6 & 5.5 & - & - & - & - \\
\hline
\end{tabular}

TABLE III

Proposed EXPANSION PLAN IN SCENARIo 1 FOR IEEE RTS

\begin{tabular}{ccccccccc}
\hline \hline Corr. & $n_{\mathrm{i}}$ & $V_{i}(\mathrm{kV})$ & Corr. & $n_{i}$ & $V_{i}$ & Corr. & $n_{i}$ & $V_{i}$ \\
\hline $1-2$ & 1 & 138 & $2-7$ & 1 & 138 & $6-10$ & 1 & 138 \\
$1-8$ & 2 & 138 & $2-9$ & 2 & 138 & $7-8$ & 1 & 138 \\
$1-9$ & 1 & 138 & $3-10$ & 1 & 138 & $11-17$ & 1 & 230 \\
$2-3$ & 2 & 138 & $5-7$ & 1 & 138 & $13-14$ & 1 & 230 \\
$2-4$ & 1 & 138 & $6-8$ & 1 & 138 & - & - & - \\
\hline \hline
\end{tabular}

TABLE IV

The Costs (MILLION \$) IN SCENARIO 1 FOR IEEE RTS

\begin{tabular}{ccc}
\hline \hline $\begin{array}{l}\text { Expansion cost of the } \\
\text { transmission system } \quad \begin{array}{c}\text { Construction cost of new lines } \\
\text { Replacement cost of existing lines }\end{array}\end{array}$ & $\begin{array}{c}27.85 \\
4.9\end{array}$ \\
\hline Expansion cost of substations & 3.5 \\
Active losses cost & 11.44 \\
Maintenance cost & 0 \\
Preventive repair cost & 0.071 \\
Corrective repair cost & 0.105 \\
Cost of LS due to transient forced outages & 0.615 \\
Cost of ENS due to permanent forced outages & 18.9 \\
Cost of ENS due to planned outages & 6.54 \\
Total cost of transmission network & 73.92 \\
\hline \hline
\end{tabular}

needed to be added to the network are listed in Table III. Also, the existing corridors $4-9,12-23,15-16,20-23$, and $21-22$ needed to be replaced by new transmission lines because their initial operation periods were greater than their regular lifetimes minus the planning horizon year. In addition, a new 138/230 kV substation had to be constructed in corridor 3-24. The expansion, operation, and reliability costs of the network are provided in Table IV.

2) Scenario 2: In this scenario, the reliability effects of line maintenance and loading on the TNEP problem were considered $\left(k_{i j} \geq 1, k_{i j}^{p r}\left\langle 1, k_{i j}^{c r}\left\langle 1\right.\right.\right.$ and $\rho_{i j}\langle 1)$. The proposed idea was applied to the network under study, and results are provided in Tables $\mathrm{V}$ to VIII. Also, the convergence curves of the both scenarios are
TABLE V

VALUE OF COST COEFFICIENTS FOR EXISTING LINES OF IEEE RTS

\begin{tabular}{lccccccccc}
\hline \hline Corr. & $k_{i j}$ & $k_{i j}^{p r}$ & $k_{i j}^{c r}$ & $k_{i j}^{\mathrm{Max}}$ & Corr. & $k_{i j}$ & $k_{i j}^{p r}$ & $k_{i j}^{c r}$ & $k_{i j}^{M a x}$ \\
\hline $1-2$ & 10.1 & 0.23 & 0.29 & 10.1 & $12-23$ & 1 & 0.57 & 0.5 & 31 \\
$1-3$ & 6.2 & 0.26 & 0.74 & 15.7 & $13-23$ & 9.2 & 0.22 & 0.63 & 19 \\
$1-5$ & 8.75 & 0.26 & 0.63 & 15.7 & $14-16$ & 8.2 & 0.22 & 0.7 & 19 \\
$2-4$ & 8.45 & 0.26 & 0.65 & 15.7 & $15-16$ & 1 & 0.51 & 0.5 & 20.8 \\
$2-6$ & 3.8 & 0.2 & 0.4 & 6.5 & $15-21$ & 9.2 & 0.21 & 0.58 & 17.3 \\
$3-9$ & 10.8 & 0.24 & 0.37 & 12 & $15-24$ & 10 & 0.22 & 0.6 & 19 \\
$4-9$ & 1 & 0.64 & 0.5 & 26.1 & $16-17$ & 8.5 & 0.2 & 0.55 & 15.8 \\
$5-10$ & 8.6 & 0.26 & 0.64 & 15.7 & $16-19$ & 6.1 & 0.16 & 0.39 & 10 \\
$6-10$ & 10.1 & 0.23 & 0.29 & 10.1 & $17-18$ & 4.4 & 0.14 & 0.34 & 7.3 \\
$7-8$ & 15.7 & 0.26 & 0.36 & 15.7 & $17-22$ & 6.5 & 0.19 & 0.53 & 13.2 \\
$8-9$ & 7.4 & 0.24 & 0.53 & 12 & $18-21$ & 4 & 0.17 & 0.55 & 11 \\
$8-10$ & 8.4 & 0.26 & 0.65 & 15.7 & $19-20$ & 7.7 & 0.21 & 0.63 & 17.3 \\
$11-13$ & 14.5 & 0.19 & 0.28 & 14.5 & $20-23$ & 1 & 0.53 & 0.5 & 22.9 \\
$11-14$ & 10 & 0.22 & 0.6 & 19 & $21-22$ & 1 & 0.54 & 0.5 & 25.2 \\
$12-13$ & 10 & 0.22 & 0.6 & 19 & - & - & - & - & - \\
\hline \hline
\end{tabular}

TABLE VI

PROPOSED EXPANSION PLAN IN SCENARIO 2 FOR IEEE RTS

\begin{tabular}{ccccccccc}
\hline \hline Corr. & $n_{i}$ & $V_{i}(\mathrm{kV})$ & Corr. & $n_{i}$ & & Corr. & $n_{i}$ & $V_{i}$ \\
\hline $1-2$ & 1 & 138 & $2-7$ & 1 & 138 & $6-8$ & 1 & 138 \\
$1-4$ & 1 & 138 & $2-9$ & 1 & 138 & $6-10$ & 1 & 138 \\
$1-7$ & 1 & 138 & $3-4$ & 1 & 138 & $7-8$ & 1 & 138 \\
$1-8$ & 2 & 138 & $3-10$ & 1 & 138 & $11-17$ & 1 & 230 \\
$1-9$ & 1 & 138 & $5-7$ & 1 & 138 & $13-14$ & 1 & 230 \\
$2-3$ & 2 & 138 & $5-10$ & 1 & 138 & - & - & - \\
\hline \hline
\end{tabular}

illustrated in Fig. 2 to show the performance of the algorithm. In addition, the construction of a new $138 / 230 \mathrm{kV}$ substation in corridor 3-24 and the replacement of existing lines in corridors 4-9, $12-23,15-16,20-23$, and 21-22 with new lines were required.

Although construction cost of new lines for the proposed plan, which considers reliability effects of line maintenance and loading is US\$150000 more than another configuration, total load shedding decreases 46\% (396 MW) in Scenario 2 because of the reduction in lines' loading (see Table XVI of [19] for more details). This fact led to a savings of US $\$ 240000$ in losses cost. In addition, the replacement cost of the existing lines in Scenario 1's configuration was equal to that of Scenario 2 because both Scenarios had the same initial operation periods and regular line lifetimes. However, in Scenario 2, US\$235000 was allocated for maintaining the existing transmission lines. Table $\mathrm{V}$ shows that the maintenance cost coefficients for most of the existing transmission lines increased considerably. For example, $k_{i j}$ for the lines of corridors $1-2,6-10,7-8$, and 11-13 not only increased, but approached its maximum value. In Scenario 2 , an increase of US\$235000 in the maintenance cost led to a reduction of US\$96000 in the preventive and corrective repair costs. The reduction of the repair cost coefficients $\left(k_{i j}^{p r}\right.$ and $\left.k_{i j}^{c r}\right)$ reflected this reality. Also, it was assumed that all of the lines replaced with new ones (lines in corridors 4-9, 12-23, 15-16, 20-23, and 21-22) would require essential maintenance actions (fixed maintenance $\operatorname{cost}\left(k_{i j}=1\right)$ ) during their operational lifetime. The transient and permanent forced outage rates of these lines due to maintenance $\left(\lambda_{m i}^{t}\right.$ and $\left.\lambda_{m i j}^{f}\right)$ were determined by 
TABLE VII

NEW OUTAGE RATES (1/YEAR) AND DURATIONS (H) OF RTS' EXISTING LINES

\begin{tabular}{|c|c|c|c|c|c|c|c|}
\hline Corridor & $\lambda_{m i j}^{t}$ & $\lambda_{m i j}^{f}$ & $\lambda_{i j}^{t}$ & $\lambda_{i j}^{f}$ & $\mu_{i j}$ & $r_{i j}^{c r}$ & $r_{i j}^{p r}$ \\
\hline $1-2$ & 0 & 0.07 & 0 & 0.17 & 0.61 & 5.3 & 2.7 \\
\hline $1-3$ & 1.72 & 0.38 & 2.36 & 0.45 & 0.45 & 3.3 & 1.7 \\
\hline $1-5$ & 0.5 & 0.2 & 1 & 0.3 & 0.2 & 3.3 & 1.7 \\
\hline $2-4$ & 0.76 & 0.25 & 1.2 & 0.32 & 0.27 & 3.3 & 1.7 \\
\hline $2-6$ & 0.7 & 0.19 & 1.75 & 0.35 & 0.3 & 3.6 & 1.8 \\
\hline $3-9$ & 0.13 & 0.14 & 0.77 & 0.24 & 0.24 & 3.3 & 1.7 \\
\hline 4-9 & 0.7 & 0.18 & 0.75 & 0.19 & 0.56 & 10 & 5 \\
\hline $5-10$ & 0.52 & 0.22 & 0.7 & 0.25 & 0.2 & 3.3 & 1.7 \\
\hline $6-10$ & 0 & 0.09 & 0 & 0.15 & 0.62 & 11.7 & 5.8 \\
\hline $7-8$ & 0 & 0.11 & 0.58 & 0.25 & 0.14 & 3.3 & 1.7 \\
\hline $8-9$ & 0.76 & 0.23 & 0.83 & 0.24 & 0.33 & 3.3 & 1.7 \\
\hline $8-10$ & 1 & 0.28 & 1.2 & 0.3 & 0.36 & 3.3 & 1.7 \\
\hline $11-13$ & 0 & 0.11 & 0.54 & 0.3 & 0.11 & 3.7 & 1.8 \\
\hline $11-14$ & 0.29 & 0.23 & 0.3 & 0.24 & 0.12 & 3.7 & 1.8 \\
\hline $12-13$ & 0.33 & 0.24 & 0.64 & 0.35 & 0.13 & 3.7 & 1.8 \\
\hline $12-23$ & 0.8 & 0.26 & 1 & 0.34 & 0.6 & 11 & 5.5 \\
\hline $13-23$ & 0.68 & 0.3 & 0.7 & 0.31 & 0.22 & 3.7 & 1.8 \\
\hline $14-16$ & 0.36 & 0.25 & 0.46 & 0.29 & 0.12 & 3.7 & 1.8 \\
\hline 15-16 & 0.15 & 0.16 & 0.19 & 0.21 & 0.16 & 11 & 5.5 \\
\hline $15-21$ & 0.3 & 0.24 & 0.62 & 0.34 & 0.13 & 3.7 & 1.8 \\
\hline $15-24$ & 0.37 & 0.25 & 0.7 & 0.35 & 0.14 & 3.7 & 1.8 \\
\hline $16-17$ & 0.15 & 0.19 & 0.31 & 0.29 & 0.08 & 3.7 & 1.8 \\
\hline $16-19$ & 0.1 & 0.13 & 0.17 & 0.19 & 0.06 & 3.7 & 1.8 \\
\hline $17-18$ & 0.04 & 0.11 & 0.14 & 0.24 & 0.04 & 3.7 & 1.8 \\
\hline $17-22$ & 0.68 & 0.28 & 1 & 0.36 & 0.22 & 3.7 & 1.8 \\
\hline $18-21$ & 0.18 & 0.1 & 0.19 & 0.19 & 0.06 & 3.7 & 1.8 \\
\hline 19-20 & 0.33 & 0.14 & 0.24 & 0.28 & 0.11 & 3.7 & 1.8 \\
\hline $20-23$ & 0.2 & 0.17 & 0.17 & 0.27 & 0.19 & 11 & 5.5 \\
\hline $21-22$ & 0.6 & 0.22 & 0.22 & 0.3 & 0.44 & 11 & 5.5 \\
\hline
\end{tabular}

TABLE VIII

THE Costs (MILlion \$) IN SCENARIO 2 FOR IEEE RTS

\begin{tabular}{|c|c|c|}
\hline $\begin{array}{l}\text { Expansion cost of the } \\
\text { transmission system }\end{array}$ & $\begin{array}{l}\text { Construction cost of new lines } \\
\text { Replacement cost of existing lines }\end{array}$ & $\begin{array}{l}28 \\
4.9\end{array}$ \\
\hline \multicolumn{2}{|c|}{ Expansion cost of substations } & 3.5 \\
\hline \multicolumn{2}{|c|}{ Active losses cost } & 11.2 \\
\hline \multicolumn{2}{|c|}{ Maintenance cost } & 0.235 \\
\hline \multicolumn{2}{|c|}{ Preventive repair cost } & 0.02 \\
\hline \multicolumn{2}{|c|}{ Corrective repair cost } & 0.06 \\
\hline \multicolumn{2}{|c|}{ Cost of LS due to transient forced outages } & 0.185 \\
\hline \multicolumn{2}{|c|}{ Cost of ENS due to permanent forced outages } & 5 \\
\hline \multicolumn{2}{|c|}{ Cost of ENS due to planned outages } & 0.37 \\
\hline \multicolumn{2}{|c|}{ Total cost of transmission network } & 53.47 \\
\hline
\end{tabular}

replacing $k_{i j}=1$ and $\alpha_{i j}=0$ in (26) and (27), respectively (see Table VII). Table VII shows that the allocation of maintenance costs led to a decrease in forced and planned outage rates and durations, and a reduction in repair costs (both preventive and corrective). Furthermore, the transient forced outage rates of some transmission lines were reduced to zero. Moreover, the average permanent forced outage rate of existing lines was reduced from 0.34 (see column 4 of Table 11 in [22]) in Scenario 1 to 0.28 in Scenario 2 (refer to column 5 of Table VII). In addition, the permanent forced interruption time (i.e., the duration of corrective repairs) decreased by $5 \mathrm{~h}$ on average (compare column 5 of Table 11 in [22] to column 7 of Table VII), and the average planned outage duration was reduced by $2 \mathrm{~h}$ (compare

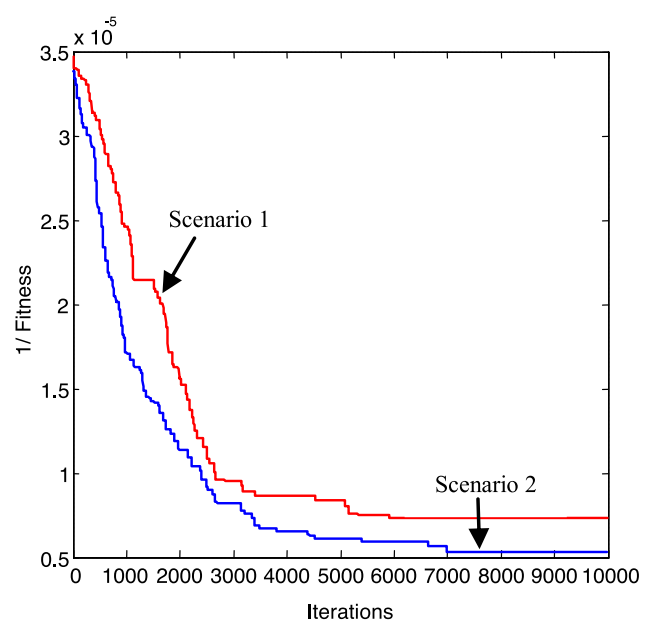

Fig. 2. Convergence curves of the algorithm in both scenarios of RTS.

columns 4 and 8 of Table II with column 8 of Table VII). This fact and reduction of load shedding in Scenario 2 caused the costs of LS and energy not supplied to decrease from US $\$ 26.05$ million to US $\$ 5.55$ million in total. In simple terms, considering the reliability effects of line maintenance on TNEP led to US $\$ 20.5$ million savings in reliability costs. Overall, it can be concluded that applying the arrangement proposed by Scenario 2 was less expensive because it yielded US $\$ 20.45$ million in cost savings compared to Scenario 1. The reduction of existing lines' loading, in addition to a decrease in load shedding, network losses, forced outage rates, and repair costs, as well as coherence among line loading, maintenance, and forced outages ((52) and (53)), and the relationships between line maintenance and repairs show that each component of cost function (1) efficiently affects the other terms of the objective function. This important characteristic, the previously mentioned advantages, the large savings in total cost, and a considerable increase in transmission system reliability show that the proposed framework is an effective model for TNEP. Fig. 2 shows that the algorithm converged after 5904 and 7003 iterations in Scenarios 1 and 2, respectively. The solutions were obtained within 3 $\mathrm{h}$ in Scenario 1 and $10 \mathrm{~h}$ in Scenario 2 on an Intel Core i5-M480 processor at $2.67 \mathrm{GHz}$ and $4 \mathrm{~GB}$ of RAM. In Scenario 1, 141 integer variables were optimized by the GA within 5904 iterations. In each iteration, 17 continuous variables (load shedding) were minimized by (64) using the fmincon function for 29 line outages. In simple terms, in each iteration of the GA, 29 existing lines were disconnected from the network one by one, and each time, 17 variables of LS were minimized. In Scenario 2, 141 integer variables were optimized by the GA within 7003 iterations. In each iteration, 29 new continuous variables $\left(k_{i j}\right)$ were optimized by (65) using the fmincon function in addition to 17 variables of LS for 29 outages. The reasons for the longer computation time in Scenario 2 are that minimizing $k_{i j}$ in each iteration was time-consuming and all variables of Scenario 1 (141 unknown integers and 17 continuous variables) and 29 variables of $k_{i j}$ were optimized for 1099 additional iterations $(7003-5904=1099)$. 
TABLE IX

OPERATION PERIODS (YEAR), AS WELL AS PLANNED AND FoRCED OUTAGE RATES (1/YEAR) FOR IEEE 30-BUS SYSTEM

\begin{tabular}{lccccccccc}
\hline \hline Corr. & $n_{i j}^{l 0}$ & $\underline{\mu_{i j}}$ & $\lambda_{i j}^{f}$ & $\underline{\lambda_{i j}^{t}}$ & Corr. & $n_{i j}^{l 0}$ & $\underline{\mu_{i j}}$ & $\lambda_{i j}^{f}$ & $\lambda_{i j}^{t}$ \\
\hline $1-2$ & 10 & 0.6 & 0.3 & 0.82 & $12-13$ & 13 & 1.2 & 0.42 & 2 \\
$1-3$ & 15 & 1.6 & 0.4 & 2.64 & $12-14$ & 8 & 2.1 & 0.58 & 3.64 \\
$2-4$ & 15 & 1.5 & 0.4 & 2.48 & $12-15$ & 5 & 1.1 & 0.4 & 1.85 \\
$2-5$ & 15 & 1.6 & 0.5 & 2.82 & $12-16$ & 11 & 1.7 & 0.5 & 2.83 \\
$2-6$ & 5 & 1.5 & 0.4 & 2.51 & $14-15$ & 9 & 1.7 & 0.5 & 2.85 \\
$3-4$ & 12 & 0.4 & 0.2 & 0.53 & $15-18$ & 14 & 1.8 & 0.52 & 3.1 \\
$4-6$ & 20 & 0.4 & 0.2 & 0.58 & $15-23$ & 17 & 1.7 & 0.5 & 2.9 \\
$4-12$ & 15 & 2.1 & 0.5 & 3.64 & $16-17$ & 18 & 1.6 & 0.49 & 2.75 \\
$5-7$ & 10 & 1 & 0.3 & 1.64 & $18-19$ & 18 & 1.1 & 0.4 & 1.85 \\
$6-7$ & 15 & 0.75 & 0.3 & 1.2 & $19-20$ & 17 & 0.6 & 0.3 & 0.87 \\
$6-8$ & 12 & 0.45 & 0.2 & 0.61 & $21-22$ & 14 & 0.3 & 0.25 & 0.34 \\
$6-9$ & 15 & 1.7 & 0.5 & 2.96 & $22-24$ & 15 & 1.5 & 0.47 & 2.5 \\
$6-10$ & 12 & 4.5 & 1 & 7.92 & $23-24$ & 16 & 2.2 & 0.6 & 3.85 \\
$6-28$ & 15 & 0.9 & 0.3 & 1.37 & $24-25$ & 8 & 2.7 & 0.68 & 4.7 \\
$8-28$ & 15 & 1.7 & 0.5 & 2.85 & $25-26$ & 3 & 3 & 0.75 & 5.42 \\
$9-10$ & 20 & 1 & 0.3 & 1.58 & $25-27$ & 20 & 1.7 & 0.51 & 2.97 \\
$9-11$ & 15 & 1.7 & 0.5 & 2.96 & $27-28$ & 25 & 3.2 & 0.78 & 5.65 \\
$10-17$ & 15 & 0.8 & 0.3 & 1.21 & $27-29$ & 7 & 3.4 & 0.8 & 5.91 \\
$10-20$ & 16 & 1.75 & 0.5 & 2.98 & $27-30$ & 12 & 4.8 & 1.06 & 8.6 \\
$10-21$ & 14 & 0.7 & 0.3 & 1.05 & $29-30$ & 10 & 3.6 & 0.85 & 6.45 \\
$10-22$ & 15 & 1.3 & 0.4 & 2.14 & - & - & - & - & - \\
\hline \hline
\end{tabular}

3) Scenario 3: The aim of this scenario is to compare the results of Scenarios 1 and 2 with those of [19] for RTS to show differences in models and case studies. The comparison between the results of the first scenarios in both papers reveals that the configuration proposed by the present model, even without considering line loading and maintenance effects, is US\$56.28 million less expensive, because of the US\$58.8 million decrease in the expansion cost of the transmission system. The reasons for this significant reduction are the US\$27.82 million and US\$31 million savings in replacement and construction costs because of the considerable decrease in the number of replaced (17 lines fewer) and new transmission lines, respectively. The modification of the arrangement of new transmission lines led to a US\$1.49 million decrease in active losses cost. In Scenario 1 of this paper, the model was solved with no maintenance, while in [19], initial maintenance actions (fixed maintenance cost) were considered in order to provide the minimum life expectancies (regular lifetimes) for existing lines. Also, in this scenario, a number of existing lines that required initial preventive and corrective repairs (fixed repair costs) are 17 lines fewer than that of [19] $(22-5=17)$. As was previously mentioned, preventive repair is quite inexpensive and more frequent than corrective repair. However, in the previous paper, the number of repairs was considered to be preventive, while the cost was corrective. This subject and the fewer number of lines needed for initial repairs, as well as the dependence of fixed preventive and corrective repair costs on a number of planned and forced outages ((11) and (12)), led to a decrease in the repair costs, considerably in Scenario 1 of this paper. The most important distinction of the present framework with regard to the model of [19] is way of reliability formulation. The previous paper proposed a probabilistic model based on load shedding, VOLL, the lines failure rate (permanent forced outage rate), and MTTR
TABLE X

VOLL (\$/MW) AND COST OF ENS (\$/MWH) FOR IEEE 30-BUS SYSTEM

\begin{tabular}{lccccccc}
\hline \hline $\mathrm{Bu}$ & VOLL & $c e_{n}^{p}$ & $c e_{n}^{f}$ & $\mathrm{Bu}$ & VOLL & $c e_{n}^{p}$ & $c e_{n}^{f}$ \\
\hline 3 & 950 & 380 & 3800 & 18 & 2100 & 840 & 8400 \\
5 & 850 & 340 & 3400 & 19 & 1700 & 680 & 6800 \\
7 & 1600 & 640 & 6400 & 20 & 2775 & 1110 & 11100 \\
8 & 650 & 260 & 2600 & 21 & 875 & 350 & 3500 \\
10 & 625 & 250 & 2500 & 23 & 2925 & 1170 & 11700 \\
12 & 1200 & 480 & 4800 & 24 & 1625 & 650 & 6500 \\
13 & 1100 & 440 & 4400 & 25 & 1125 & 450 & 4500 \\
14 & 1500 & 600 & 6000 & 27 & 750 & 300 & 3000 \\
15 & 1550 & 620 & 6200 & 29 & 1000 & 400 & 4000 \\
16 & 1700 & 680 & 6800 & - & - & - & - \\
\hline \hline
\end{tabular}

TABLE XI

Proposed EXPANSION PLAN IN SCENARIO 1 FOR IEEE 30-BUS SySTEM

\begin{tabular}{lccccccccc}
\hline \hline Corr. & $n_{i}$ & Corr. & $n_{i}$ & Corr. & $n_{i}$ & Corr. & $n_{i}$ & Corr. & $n_{i}$ \\
\hline $1-4$ & 2 & $6-11$ & 1 & $9-22$ & 1 & $14-26$ & 1 & $22-25$ & 2 \\
$3-4$ & 1 & $7-13$ & 2 & $10-22$ & 1 & $15-16$ & 1 & - & - \\
$3-10$ & 1 & $8-19$ & 1 & $10-26$ & 1 & $16-27$ & 1 & - & - \\
$4-13$ & 1 & $9-14$ & 1 & $10-28$ & 1 & $21-23$ & 1 & - & - \\
\hline \hline
\end{tabular}

(planned outage rate) for transmission reliability. However, in the current research, in addition to the previously mentioned components, permanent forced and planned outage durations, the transient forced outage rate (it is more frequent than the permanent one), costs of one MWh ENS for planned (it was 4 times bigger than VOLL in Table I) and forced outages were added to reliability formulation. This issue caused the reliability cost to increase by US\$11 million in the current Scenario 1. Although the construction cost of new lines and the active losses cost in Scenario 2 of the current research are US\$41.17 million and US\$760000 less than the corresponding costs in [19], the replacement cost increased by US\$4.9 million. The reason is that in the previous paper, the lines' lives (life expectancies) were expanded to gain more VTSs (higher value of transmission system), and therefore, no line replacement was required. This fact caused a large increase in maintenance and repair costs in Scenario 2 of [19]. In the current research, 5 corridors were needed for maintenance, while in Scenario 2 of [19], maintenance was necessary for 29 corridors. Moreover, further maintenance is not required here because the lines' lives were considered to be fixed. Thus, a low maintenance cost was calculated here. In addition, the total cost of load shedding in Scenario 2 of the present paper is US\$4.24 million less than the related cost in [19]. This fact shows the efficiency of the present model in studying the reliability effects of maintenance on TNEP. Finally, it can be said that, although the proposed model forbore from US\$35.16 million profit due to VTS, it is still more economic than the configuration proposed in Scenario 2 of [19], because it provides an additional US\$38.32 million in savings.

\section{B. IEEE 30-bus Test System}

The IEEE 30-bust network with 19 load busses, 41 existing lines, and 435 corridors $\left(\left|\Omega^{c}\right|=435\right.$ and $\left.\left|\Omega^{s}\right|=0\right)$ was used 
TABLE XII

THE Costs (MILLION \$) IN SCENARIO 1 FOR IEEE 30-BUS SySTEM

\begin{tabular}{rcc}
\hline \hline $\begin{array}{l}\text { Expansion cost of the } \\
\text { transmission system }\end{array}$ & $\begin{array}{c}\text { Construction cost of new lines } \\
\text { Replacement cost of existing lines }\end{array}$ & $\begin{array}{c}57.6 \\
6.1\end{array}$ \\
\hline Active losses cost & 13.3 \\
Maintenance cost & 0 \\
Preventive repair cost & 0.4 \\
Corrective repair cost & 0.3 \\
Cost of LS due to transient forced outages & 1.3 \\
Cost of ENS due to permanent forced outages & 12.3 \\
Cost of ENS due to planned outages & 1.62 \\
Total cost of transmission network & 92.92 \\
\hline
\end{tabular}

TABLE XIII

Proposed EXPANSION Plan IN SCENARIO 2 FOR IEEE 30-BUS SySTEM

\begin{tabular}{lccccccccc}
\hline \hline Corr. & $n_{i}$ & Corr. & $n_{i}$ & Corr. & $n_{i}$ & Corr. & $n_{i}$ & Corr. & $n_{i}$ \\
\hline $1-3$ & 1 & $4-13$ & 1 & $8-19$ & 1 & $10-28$ & 1 & $21-23$ & 1 \\
$1-4$ & 2 & $6-11$ & 1 & $9-22$ & 1 & $14-26$ & 1 & $21-24$ & 1 \\
$3-4$ & 1 & $7-13$ & 2 & $10-22$ & 1 & $15-16$ & 1 & $22-25$ & 1 \\
$3-10$ & 1 & $8-12$ & 1 & $10-26$ & 1 & $16-27$ & 1 & - & - \\
\hline \hline
\end{tabular}

TABLE XIV

VALUE OF COST COEFFICIENTS FOR EXISTING LINES OF IEEE 30-BUS SYSTEM

\begin{tabular}{lccccccccc}
\hline \hline Corr. & $k_{i j}$ & $k_{i j}^{p r}$ & $k_{i j}^{c r}$ & $k_{i j}^{\mathrm{Max}}$ & Corr. & $k_{i j}$ & $k_{i j}^{p r}$ & $k_{i j}^{c r}$ & $k_{i j}^{\mathrm{Max}}$ \\
\hline $1-2$ & 10.1 & 0.23 & 0.29 & 10.1 & $12-13$ & 1.8 & 0.49 & 0.87 & 13.1 \\
$1-3$ & 15.7 & 0.26 & 0.36 & 15.7 & $12-14$ & 1.6 & 0.48 & 0.7 & 8.5 \\
$2-4$ & 15.7 & 0.26 & 0.36 & 15.7 & $12-15$ & 1.4 & 0.47 & 0.6 & 6.5 \\
$2-5$ & 15.7 & 0.26 & 0.36 & 15.7 & $12-16$ & 1.7 & 0.48 & 0.8 & 11 \\
$2-6$ & 6.5 & 0.2 & 0.22 & 6.5 & $14-15$ & 1.6 & 0.48 & 0.74 & 9.3 \\
$3-4$ & 12 & 0.24 & 0.31 & 12 & $15-18$ & 1.9 & 0.49 & 0.9 & 14.3 \\
$4-6$ & 1 & 0.64 & 0.5 & 26.1 & $15-23$ & 1 & 0.61 & 0.5 & 19 \\
$4-12$ & 14.8 & 0.26 & 0.39 & 15.7 & $16-17$ & 1 & 0.62 & 0.5 & 21 \\
$5-7$ & 10.1 & 0.23 & 0.29 & 10.1 & $18-19$ & 1 & 0.62 & 0.5 & 21 \\
$6-7$ & 2 & 0.49 & 0.94 & 15.7 & $19-20$ & 1 & 0.61 & 0.5 & 19 \\
$6-8$ & 1.8 & 0.48 & 0.84 & 12 & $21-22$ & 1.9 & 0.49 & 0.9 & 14.3 \\
$6-9$ & 2 & 0.49 & 0.94 & 15.7 & $22-24$ & 2 & 0.49 & 0.94 & 15.7 \\
$6-10$ & 12 & 0.24 & 0.31 & 12 & $23-24$ & 1 & 0.6 & 0.5 & 17.2 \\
$6-28$ & 2 & 0.49 & 0.94 & 15.7 & $24-25$ & 1.6 & 0.48 & 0.7 & 8.5 \\
$8-28$ & 2 & 0.49 & 0.94 & 15.7 & $25-26$ & 1.4 & 0.46 & 0.53 & 5.4 \\
$9-10$ & 1 & 0.64 & 0.5 & 26.1 & $25-27$ & 1 & 0.64 & 0.5 & 26.1 \\
$9-11$ & 15.7 & 0.26 & 0.36 & 15.7 & $27-28$ & 1 & 0.69 & 0.5 & 55.2 \\
$10-17$ & 15.7 & 0.26 & 0.36 & 15.7 & $27-29$ & 7.4 & 0.21 & 0.27 & 7.8 \\
$10-20$ & 1 & 0.6 & 0.5 & 17.2 & $27-30$ & 12 & 0.24 & 0.31 & 12 \\
$10-21$ & 1.9 & 0.49 & 0.9 & 14.3 & $29-30$ & 10 & 0.23 & 0.29 & 10 \\
$10-22$ & 15.7 & 0.26 & 0.36 & 15.7 & - & - & - & - & - \\
\hline \hline
\end{tabular}

to demonstrate the effectiveness of the proposed idea in larger case study systems. The generation and load arrangement, lines' characteristics, and configuration of this network are available in [23]. Planned and forced outage durations of existing lines and their voltage levels are considered to be $5 \mathrm{~h}, 10 \mathrm{~h}$, and $135 \mathrm{kV}$, respectively. Also, Tables IX and X describe $n_{\mathrm{ij}}{ }^{10}, \mu_{i j}$, VOLL, the cost of ENS, and permanent and transient forced outage rates of existing lines $\left(\lambda_{i j}^{f}\right.$ and $\left.\lambda_{i j}^{t}\right)$.

The proposed method is applied to the case study system in two scenarios. In Scenario 1, the TNEP problem was solved without considering maintenance, while in Scenario 2, the maintenance and line loading effects were considered.
TABLE XV

NEW OUTAGE RATES (1/YEAR) AND DURATIONS (H) OF EXISTING LINES FOR IEEE 30-BUS SYSTEM

\begin{tabular}{|c|c|c|c|c|c|c|c|}
\hline Corridor & $\lambda_{m i j}^{t}$ & $\lambda_{m i j}^{f}$ & $\lambda_{i j}^{t}$ & $\lambda_{i j}^{f}$ & $\mu_{i j}$ & $r_{i j}^{c r}$ & $r_{i j}^{p r}$ \\
\hline $1-2$ & 0 & 0.09 & 0.54 & 0.2 & 0.13 & 3.3 & 1.6 \\
\hline $1-3$ & 0 & 0.17 & 2.46 & 0.45 & 0.41 & 3.3 & 1.6 \\
\hline $2-4$ & 0 & 0.17 & 1.4 & 0.33 & 0.39 & 3.3 & 1.6 \\
\hline $2-5$ & 0 & 0.18 & 2.3 & 0.4 & 0.44 & 3.3 & 1.6 \\
\hline $2-6$ & 0 & 0.1 & 1.5 & 0.32 & 0.3 & 3.3 & 1.6 \\
\hline $3-4$ & 0 & 0.09 & 0.5 & 0.26 & 0.1 & 3.3 & 1.6 \\
\hline $4-6$ & 0.29 & 0.14 & 0.34 & 0.16 & 0.27 & 10 & 5 \\
\hline $4-12$ & 0.2 & 0.23 & 0.58 & 0.26 & 0.5 & 3.3 & 1.6 \\
\hline $5-7$ & 0 & 0.11 & 0.4 & 0.18 & 0.23 & 3.3 & 1.6 \\
\hline $6-7$ & 1.05 & 0.31 & 1.08 & 0.32 & 0.37 & 9.8 & 4.9 \\
\hline $6-8$ & 0.49 & 0.23 & 0.53 & 0.25 & 0.21 & 10 & 5 \\
\hline $6-9$ & 2.67 & 0.48 & 2.7 & 0.49 & 0.85 & 9.8 & 4.9 \\
\hline $6-10$ & 0 & 0.31 & 2.29 & 0.5 & 1.09 & 3.3 & 1.6 \\
\hline $6-28$ & 1.24 & 0.33 & 1.29 & 0.34 & 0.43 & 9.8 & 4.9 \\
\hline $8-28$ & 2.57 & 0.47 & 2.6 & 0.48 & 0.82 & 9.8 & 4.9 \\
\hline $9-10$ & 0.79 & 0.19 & 1.4 & 0.34 & 0.63 & 10 & 5 \\
\hline 9-11 & 0 & 0.18 & 1.79 & 0.38 & 0.46 & 3.3 & 1.6 \\
\hline $10-17$ & 0 & 0.12 & 0.7 & 0.25 & 0.2 & 3.3 & 1.6 \\
\hline $10-20$ & 1.49 & 0.26 & 1.79 & 0.3 & 1.05 & 10 & 5 \\
\hline $10-21$ & 0.92 & 0.29 & 1.02 & 0.31 & 0.34 & 10 & 5 \\
\hline $10-22$ & 0 & 0.15 & 1.02 & 0.28 & 0.34 & 3.3 & 1.6 \\
\hline $12-13$ & 1.68 & 0.36 & 1.7 & 0.37 & 0.59 & 10 & 5 \\
\hline $12-14$ & 2.4 & 0.41 & 2.9 & 0.47 & 1 & 10 & 5 \\
\hline $12-15$ & 1.06 & 0.24 & 1.25 & 0.28 & 0.53 & 10 & 5 \\
\hline $12-16$ & 2.18 & 0.4 & 2.28 & 0.41 & 0.8 & 10 & 5 \\
\hline $14-15$ & 2 & 0.37 & 2.3 & 0.41 & 0.8 & 10 & 5 \\
\hline $15-18$ & 2.71 & 0.48 & 2.78 & 0.49 & 0.9 & 10 & 5 \\
\hline $15-23$ & 1.45 & 0.25 & 1.46 & 0.26 & 1.03 & 10 & 5 \\
\hline $16-17$ & 1.37 & 0.24 & 2.18 & 0.39 & 1 & 10 & 5 \\
\hline $18-19$ & 0.92 & 0.2 & 1.61 & 0.35 & 0.7 & 10 & 5 \\
\hline 19-20 & 0.43 & 0.15 & 0.79 & 0.28 & 0.36 & 10 & 5 \\
\hline $21-22$ & 0.29 & 0.23 & 0.31 & 0.24 & 0.14 & 10 & 5 \\
\hline $22-24$ & 2.3 & 0.44 & 2.37 & 0.45 & 0.74 & 9.8 & 4.9 \\
\hline $23-24$ & 1.93 & 0.3 & 2.7 & 0.42 & 1.34 & 10 & 5 \\
\hline $24-25$ & 3.15 & 0.48 & 3.2 & 0.49 & 1.28 & 10 & 5 \\
\hline $25-26$ & 2.74 & 0.4 & 2.78 & 0.41 & 1.42 & 10 & 5 \\
\hline $25-27$ & 1.49 & 0.26 & 1.8 & 0.31 & 1.1 & 10 & 5 \\
\hline $27-28$ & 2.82 & 0.39 & 3.3 & 0.45 & 2.2 & 10 & 5 \\
\hline $27-29$ & 0.21 & 0.22 & 1.4 & 0.34 & 0.71 & 3.3 & 1.6 \\
\hline $27-30$ & 0 & 0.34 & 0.7 & 0.4 & 1.18 & 3.3 & 1.6 \\
\hline $29-30$ & 0 & 0.24 & 0.5 & 0.29 & 0.85 & 3.3 & 1.6 \\
\hline
\end{tabular}

1) Scenario 1: The TNEP problem, considering network losses and transmission reliability, was solved for $k_{i j}=0$ and $k_{i j}^{p r}=k_{i j}^{c r}=\rho_{i j}=1$. Tables XI and XII show new transmission lines and related costs for the IEEE 30-bus system, respectively. According to the operation periods in Table IX, the old lines of corridors $4-6,9-10,10-20,15-23,16-17,18-19$, 19-20, 23-24, 25-27, and 27-28 require the replacement.

2) Scenario 2: The proposed model of Scenario 1, considering line loading and the reliability effects of maintenance, was applied to the IEEE 30-bus system, and results were presented in Tables XIII to XVI. Also, similar to the previous scenario, line replacement in corridors 4-6, 9-10, 10-20, 15-23, 16-17, $18-19,19-20,23-24,25-27$, and $27-28$ is necessary. In addition, Fig. 3 illustrates the convergence process of the algorithm in both scenarios.

The construction cost of new lines in Scenario 2 is US\$400000 more than that of another scenario, but it causes the total load shedding to decrease by $75 \%$ (790 MW). According to 
TABLE XVI

The Costs (Million \$) In SCENARIO 2 For IEEE 30-Bus SYSTEM

\begin{tabular}{rcc}
\hline \hline $\begin{array}{l}\text { Expansion cost of the } \\
\text { transmission system }\end{array}$ & $\begin{array}{c}\text { Construction cost of new lines } \\
\text { Replacement cost of existing lines }\end{array}$ & $\begin{array}{c}58 \\
6.1\end{array}$ \\
\hline Active losses cost & 13 \\
Maintenance cost & 0.48 \\
Preventive repair cost & 0.1 \\
Corrective repair cost & 0.13 \\
Cost of LS due to transient forced outages & 0.2 \\
Cost of ENS due to permanent forced outages & 2 \\
Cost of ENS due to planned outages & 0.12 \\
Total cost of transmission network & 80.13 \\
\hline \hline
\end{tabular}

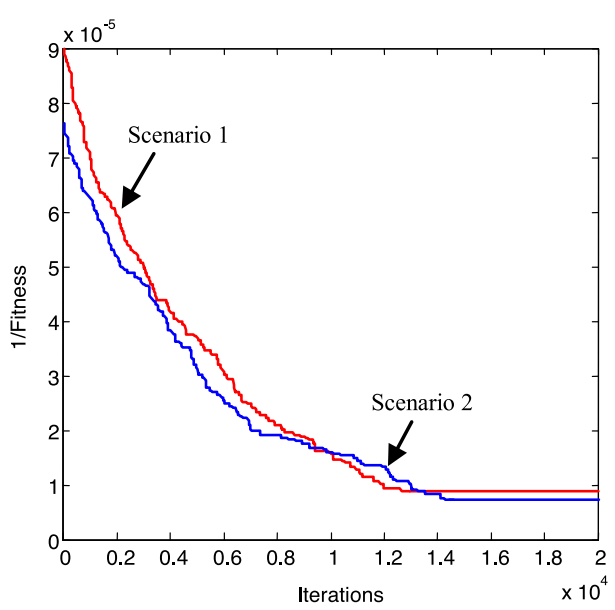

Fig. 3. Convergence curves for both scenarios of IEEE 30-bus system.

Table XIV, the maintenance cost coefficients of many existing lines increased (the maintenance cost coefficients of some corridors $(1-2,1-3,2-4,2-5,2-6,3-4,5-7,6-10,9-11,10-17$, $10-22,27-30$, and 29-30) reached their maximum values). This issue caused the maintenance cost to increase by US $\$ 480000$ and the repair costs to decrease by US $\$ 230000$. In addition, there was a decrease in the forced and planned outage rates and durations ( $2.5 \mathrm{~h}$ for $r_{i j}^{c r}$ and $1.25 \mathrm{~h}$ for $r_{i j}^{p r}$ on average). However, the number of lines by which their forced and planned outage durations were reduced is less than that of RTS, because their maintenance cost coefficients were between 1 and 2 $\left(1 \leq k_{i j} \leq 2\right)$. This fact caused the outage durations were set on their basic values (see (39) and (47)). Instead, transmission lines with no transient forced outages $\left(\lambda_{m i j}^{t}=0\right)$ were increased. In addition, the average permanent forced outage rate of the existing lines in Scenario 2 is reduced by $15 \%$ (it was $6 \%$ for RTS). Nevertheless, in Scenario 2, the reliability cost (LS and ENS costs) decreased by US $\$ 7.6$ million less than RTS. This fact shows the importance of outage durations in reliability calculations that were ignored by [19]. However, the configuration proposed by Scenario 2 is US $\$ 12.79$ million less expensive than that of Scenario 1.

From Fig. 3, the solution took 12762 iterations $(28 \mathrm{~h})$ and 14760 iterations ( $82 \mathrm{~h}$ ) to converge in Scenarios 1 and 2, respectively. In Scenario 1, the problem included 454 (435 integer and 19 continuous) variables. In Scenario 2, 41 variables of $k_{i j}$ were added to 454 optimization variables of Scenario 1 . In each iteration of the GA, 19 continuous variables of LS were minimized by fmincon when 41 existing lines failed one by one. At the same time, 41 variables of $k_{i j}$ are optimized.

\section{CONCLUSION}

This paper introduced a reliability-based model for transmission expansion planning considering the effects of line maintenance on line repairs and reliability costs of the transmission system, as well as effects of line loading on network reliability. The maintenance effect on transmission reliability was formulated by the cost of load shedding and energy not supplied due to the forced and planned outages of transmission lines. The effect of maintenance on the cost of load shedding was modeled via the relationship between the annual transient number of forced outages (transient forced outage rates) and the maintenance cost coefficient using load curtailment and value of lost loads. Also, a part of the maintenance effect on cost of energy not supplied was formulated through the relationship of the annual number of permanent forced outages (permanent forced outage rates) and forced outage durations (interruption times that are required for corrective repairs) to the maintenance cost coefficient, using the cost of one MWh energy not supplied due to forced outages and load curtailment. The other part was modeled via the nonlinear coherence of the annual number and duration of planned outages (preventive repair rates and duration) with maintenance cost coefficient, considering the cost of one MWh energy not supplied due to planned outages and load shedding. In addition, the reliability effects of line loading are formulated through the transient and permanent forced outage rates. The simulation results revealed the importance of the proposed TNEP model. Lines that seem old and ready to be replaced by new ones can still be economical and reliable in the long run if the required maintenance actions are carried out. Although the maintenance of existing lines is costly, it results in a decrease of $27.7 \%$ and $13.8 \%$ in the total costs of the RTS and the IEEE 30-bus system, respectively, because of the reduction in transmission system reliability costs, as well as line preventive and corrective repair expenditures.

\section{REFERENCES}

[1] P. Murugan, "Modified particle swarm optimisation with a novel initialisation for finding optimal solution to the transmission expansion planning problem," IET Gener., Transm. Distrib., vol. 6, pp. 1132-1142, 2012.

[2] H. K. Kim, "Reliability modeling and evaluation in aging power systems," M.Sc. thesis, Elect. Comput. Eng. Dept., Texas A\&M Univ., College Station, TX, USA, 2009.

[3] P. Jirutitijaroen and C. Singh, "The effect of transformer maintenance parameters on reliability and cost: A probabilistic model," Elect. Power Syst. Res., vol. 72, pp. 213-224, 2004.

[4] L. L. Garver, "Transmission network estimation using linear programming," IEEE Trans. Power App. Syst., vol. PAS-89, no. 7, pp. 1688-1697, Sep. 1970.

[5] K. J. Kim, Y. M. Park, and K. Y. Lee, "Optimal long term transmission expansion planning based on maximum principle," IEEE Trans. Power Syst., vol. 3, no. 4, pp. 1494-1501, Nov. 1988.

[6] R. Romero, R. A. Gallego, and A. Monticelli, "Transmission system expansion planning by simulated annealing," IEEE Trans. Power Syst., vol. 11, no. 1, pp. 364-369, Feb. 1996. 
[7] R. A. Gallego, A. B. Alves, A. Monticelli, and R. Romero, "Parallel simulated annealing applied to long term transmission network expansion planning," IEEE Trans. Power Syst., vol. 12, no. 1, pp. 181-188, Feb. 1997.

[8] I. D. J. Silva, M. J. Rider, R. Romero, and C. A. Murari, "Transmission network expansion planning considering uncertainness in demand," in Proc. IEEE Power Eng. Soc. General Meeting, 2005, vol. 2, pp. 14241429.

[9] S. Binato, G. C. de Oliveira, and J. L. Araujo, "A greedy randomized adaptive search procedure for transmission expansion planning," IEEE Trans. Power Syst., vol. 16, no. 2, pp. 247-253, May 2001.

[10] J. Choi, T. Mount, and R. Thomas, "Transmission system expansion plans in view point of deterministic, probabilistic and security reliability criteria," in Proc. 39th Annu. Hawaii Int. Conf. Syst. Sci., 2006, vol. 10, pp. 1-10.

[11] J. Choi, T. D. Mount, R. J. Thomas, and R. Billinton, "Probabilistic reliability criterion for planning transmission system expansions," in Proc. Inst. Elect. Eng.-Gener, Transm. Distrib., 2006, vol. 153, pp. 719-727.

[12] A. M. L. Silva, L. S. Rezende, L. A. F. Manso, and L. C. Resende, "Reliability worth applied to transmission expansion planning based on ant colony system," Int. J. Elect. Power Energy Syst., vol. 32, pp. 1077-1084, 2010 .

[13] A. M. L. Silva, L. S. Rezende, L. M. Honório, and L. A. F. Manso, "Performance comparison of metaheuristics to solve the multi-stage transmission expansion planning problem," IET Gener, Transm. Distrib., vol. 5, pp. 360-367, 2011.

[14] R. C. Leou, "A multi-year transmission planning under a deregulated market," Int. J. Elect. Power Energy Syst., vol. 33, pp. 708-714, 2011.

[15] A. Akbari Foroud, A. A. Abdoos, R. Keypour, and M. Amirahmadi, "A multi-objective framework for dynamic transmission expansion planning in competitive electricity market," Int. J. Elect. Power Energy Syst., vol. 32, pp. 861-872, 2010.

[16] H. Yu, C. Y. Chung, and K. P. Wong, "Robust transmission network expansion planning method with Taguchi's orthogonal array testing," IEEE Trans. Power Syst., vol. 26, no. 3, pp. 1573-1580, Aug. 2011.

[17] N. Gupta, R. Shekhar, and P. K. Kalra, "Congestion management based roulette wheel simulation for optimal capacity selection: Probabilistic transmission expansion planning," Int. J. Elect. Power Energy Syst., vol. 43, pp. 1259-1266, 2012

[18] J. Shortle, S. Rebennack, and F. W. Glover, "Transmission-capacity expansion for minimizing blackout probabilities," IEEE Trans. Power Syst., vol. 29, no. 1, pp. 43-52, Jan. 2014.

[19] M. Mahdavi, H. Monsef, and R. Romero, "Reliability and economic effects of maintenance on TNEP considering line loading and repair," IEEE Trans. Power Syst., vol. 31, no. 5, pp. 3381-3393, Sep. 2016.

[20] H. Shayeghi, S. Jalilzadeh, M. Mahdavi, and H. Haddadian, "Studying influence of two effective parameters on network losses in transmission expansion planning using DCGA," Energy Convers. Manage., vol. 49, pp. 3017-3024, 2008
21] H. Shayeghi, M. Mahdavi, A. Kazemi, and H. A. Shayanfar, "Studying effect of bundle lines on TNEP considering network losses using decimal codification genetic algorithm," Energy Convers. Manage., vol. 51, pp. 2685-2691, 2010.

[22] Reliability Test System Task Force of the Application of Probability Methods Subcommittee, "IEEE reliability test system," IEEE Trans. Power App. Syst., vol. PAS-98, no. 6, pp. 2047-2054, Nov. 1979.

[23] M. O. Buygi "Transmission expansion planning in deregulated power systems," Ph.D. dissertation, Elektrotechnik und Informationstechnik, Technischen Universität Darmstadt, Darmstadt, Germany, 2004.

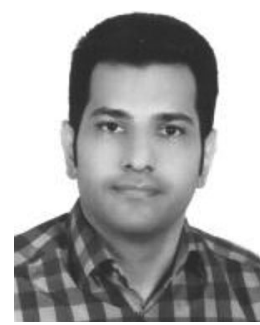

Meisam Mahdavi received the M.Sc. degree from the University of Zanjan, Zanjan, Iran, in 2008, and the Ph.D. degree from the University of Tehran, Tehran, Iran, in 2015, both in power engineering. His research interests are power system planning and operation, network reliability, maintenance of electrical equipment, and applications of artificial intelligence in power system optimization.

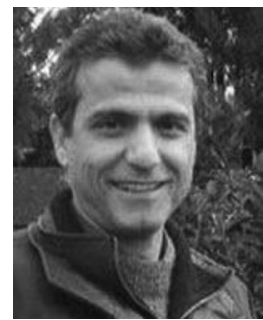

Hassan Monsef (M'15) received the B.Sc. degree from Sharif University of Technology, Tehran, Iran, in 1986, the M.Sc. (Hons.) degree from the University of Tehran, Tehran, in 1989, and the Ph.D. degree from Sharif University of Technology in 1996, all in power engineering. He is currently a Professor in electrical engineering with the University of Tehran. His research interests are power system operation and planning, reliability of power system, and integration of renewables into smart grid.

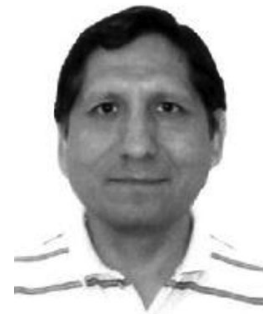

Rubén Romero (M'93-SM'08) received the B.Sc. and P.E. degrees from the National University of Engineering, Lima, Perú, in 1978 and 1984, respectively, and the M.Sc. and Ph.D. degrees from the Universidade Estadual de Campinas, Campinas, Brazil, in 1990 and 1993, respectively. He is currently a Professor in electrical engineering with the Universidade Estadual Paulista "Julio de Mesquita Filho," Ilha Solteira, Brazil. His research interests include methodologies for the optimization, planning, and control of electrical power systems; applications of artificial intelligence in power system; and operations research. 